\title{
Reflectance imaging spectroscopy and synchrotron radiation X-ray fluorescence mapping used in a technical study of The Blue Room by Pablo Picasso
}

Patricia A. Favero ${ }^{1 *}$, Jennifer Mass ${ }^{2}$, John K. Delaney ${ }^{3}$, Arthur R. Woll ${ }^{4}$, Alyssa M. Hull ${ }^{5}$, Kathryn A. Dooley ${ }^{3}$ and Adam C. Finnefrock ${ }^{6}$

\begin{abstract}
The existence of a portrait hidden beneath The Blue Room (1901) by Pablo Picasso prompted a comprehensive technical study of this early Blue period painting. Microanalysis of paint samples was combined with reflectance imaging spectroscopy (RIS) and synchrotron radiation X-ray fluorescence (SR-XRF) mapping to characterize the materials and structure of the paint layers and to understand the artist's palette and use of color in both paintings. Microanalysis of paint samples provided detailed information about pigment mixtures and paint stratigraphy while the complementary data sets provided by RIS and SR-XRF yielded important information about pigment distribution in both pictures and clarified details of the underlying painting. Overall, the comprehensive study increased understanding of both pictures and added to the growing body of knowledge about Picasso's early experimentation and evolving technique.
\end{abstract} Keywords: Picasso, Pigment identification, Infrared reflectography, Imaging spectroscopy, Multispectral, Synchrotron, $X$-ray fluorescence, Reflectance

\section{Background}

The Blue Room (Fig. 1) was painted by Pablo Picasso in 1901 during his second stay in Paris and depicts a bathing nude figure in a bedroom that has been identified as Picasso's studio at the time, at $130^{\text {ter }}$ Boulevard de Clichy in Montmartre. The painting is widely regarded as an important early example of the young Spanish artist's transition into his Blue period and has been included in a number of scholarly exhibitions and publications focusing on Picasso's early years [1-6]. The composition pays homage to a number of influences, including Vincent van Gogh, Edgar Degas, and Henri de Toulouse-Lautrec, whose famous poster of the dancer May Milton is prominently featured on the wall over the bed.

When the painting is viewed in raking light (Fig. 2), distinct surface texture and craquelure patterns that do

\footnotetext{
*Correspondence: pfavero@phillipscollection.org

1 The Phillips Collection, 1600 21st Street NW, Washington, DC 20009, USA Full list of author information is available at the end of the article
}

not match the visible composition are evident. As early as 1954, a conservator's report noted: "The paint layer is extremely thick, owing in part to the fact that the fabric is supporting two compositions, with the outlines of the first showing clearly on the present paint surface." [7]. These suggestions of another composition beneath The Blue Room encouraged the technical study of this painting.

Upon close visual examination, one sees that The Blue Room is actually thinly painted and surface brushstrokes skip over the heavier texture of underlying paint layers, leaving voids in many areas through which color is visible (Fig. 3). In addition to adding visual interest to the surface composition, the underlying colors suggest Picasso painted over another composition without applying an intermediate ground layer. Paint losses and raised cracks reveal additional areas of underlying color.

A number of cases of Picasso reusing canvases are known, particularly in his early works and many have 


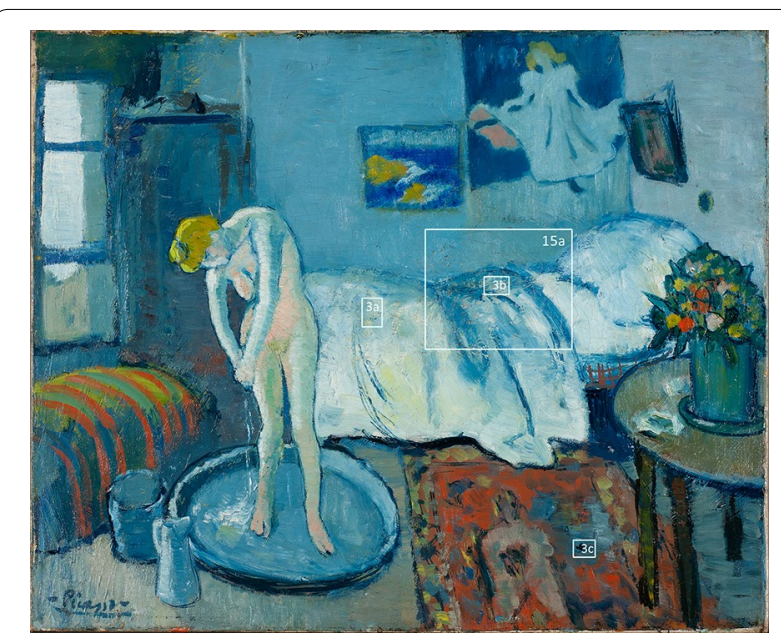

Fig. 1 The Blue Room (Le Tub) 1901, Oil on canvas, $50.5 \times 61.6 \mathrm{~cm}$. The Phillips Collection, Washington D.C. Acquired 1927. (c)2016 Estate of Pablo Picasso/Artists Rights Society (ARS), New York. The Pablo Picasso work may not be used outside of the context of this article. Reproduction of the work is prohibited by copyright laws and international conventions without the express written permission of ARS (www.arsny.com). Locations of detail images shown in Figs. 3 and 15 are outlined and labeled

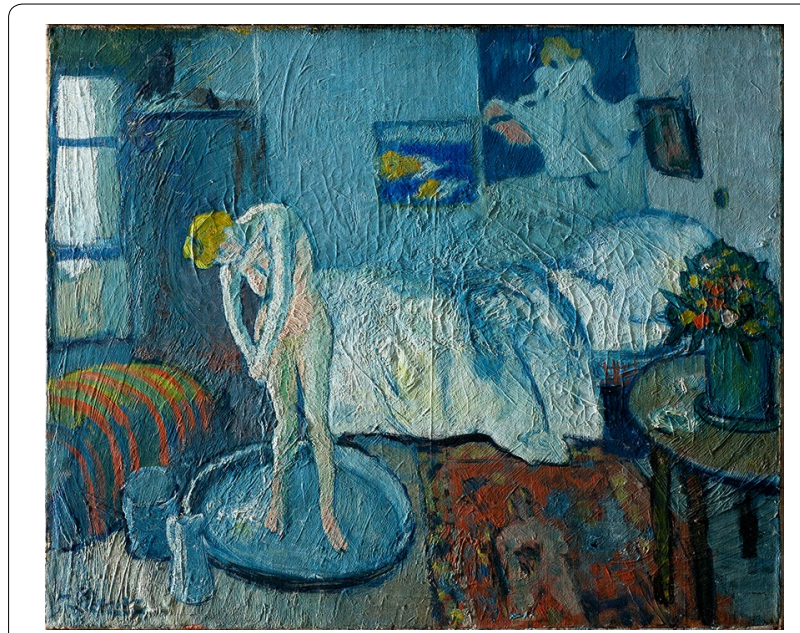

Fig. 2 The Blue Room photographed in raking light shows inconsistencies between the surface texture and the visible composition

been documented and discussed by conservators, art historians, and scientists [8-18]. Many more potential instances remain unexamined or unpublished. The present study was undertaken to learn as much as possible about Picasso's materials and his approach to painting in both The Blue Room and the underlying composition, with an aim to contribute to the increasing body of technical knowledge about Picasso's early work.

\section{Methods}

Infrared reflectography (IRR)

Infrared reflectography was performed in multiple spectral regions of the near infrared (NIR). The painting was examined using an InGaAs camera (Sensors Unlimited, Princeton, NJ; SU-320 M-1.7RT, detector wavelength 1000-1650 nm) with a Nikon AF Micro Nikkor $60 \mathrm{~mm}$ 1:2.8 lens, first with no spectral filters, then subsequently using a longwave pass interface filter [Spectrogon US, Inc., Mountain Lakes, NJ; LP filter ( 1500 to $3000 \mathrm{~nm}$ )] to limit the spectral range to $1500-1650 \mathrm{~nm}$. The NIR range was extended using a high-resolution, liquid nitrogen-cooled analog InSb $640 \times 512$ array with 24-micrometer pixels band pass limited by a cold filter that passes 1000-2450 nm (SBF-193, Santa Barbara Focal Plane, CA). The camera was used with a custom $55 \mathrm{~mm}$ lens optimized for the near infrared (Stingray $\mathrm{NH})$ and three astronomy interference filters, J (1100$1400 \mathrm{~nm}) ; \mathrm{H}(1500-1800 \mathrm{~nm})$; and $\mathrm{K}(2100-2400 \mathrm{~nm})$ [Barr Associates, MA]. The diffuse illumination system consists of two, $150 \mathrm{~W}$ tungsten halogen lamps (Lowel Pro-light with Osram FVM bulbs) with ground glass windows, placed $50^{\circ}$ from the painting normal. The light levels are controlled by a rheostat and illuminance at the artwork is $50 \mathrm{~lx}$.

\section{Portable X-ray fluorescence spectroscopy (pXRF)}

Portable X-ray fluorescence spectroscopy analysis was performed with the handheld KeyMaster TRACeR III-V $\mathrm{XRF}$ spectrometer using a rhodium tube $(40 \mathrm{kV}$ voltage, $1.2 \mu \mathrm{A}$ current, $180 \mathrm{~s}$ live time irradiation, no filter). The instrument was supported on a tripod for portable analysis. Spectra were interpreted using the PXRF1 software.

\section{Microanalysis of paint samples}

Small paint samples (approximately 100 microns in size) were taken from the edges of the painting and areas of prior loss. Samples were removed with a size 11, steel micro-scalpel blade and cast separately in mini-cube molds, approximately half-inch width each, suspended in polyester resin (Extec polyester clear resin with methyl ethyl ketone peroxide catalyst, Extec Corporation ${ }^{\circledR}$, Enfield, CT). The resin cured for $24 \mathrm{~h}$ at room temperature and under ambient light before the samples were removed. Excess casting medium was removed from the cube just up to the surface of the paint sample with a jeweler's saw (Rio Grande saw blades, laser gold). The cubes were hand-polished successively with 400- and 600-grit Buehler Carbimet paper (silicon carbide) and 1500- to 12,000-grit Micro-Mesh Inc. polishing cloths (silicon carbide) to expose the paint layers in cross-section. 


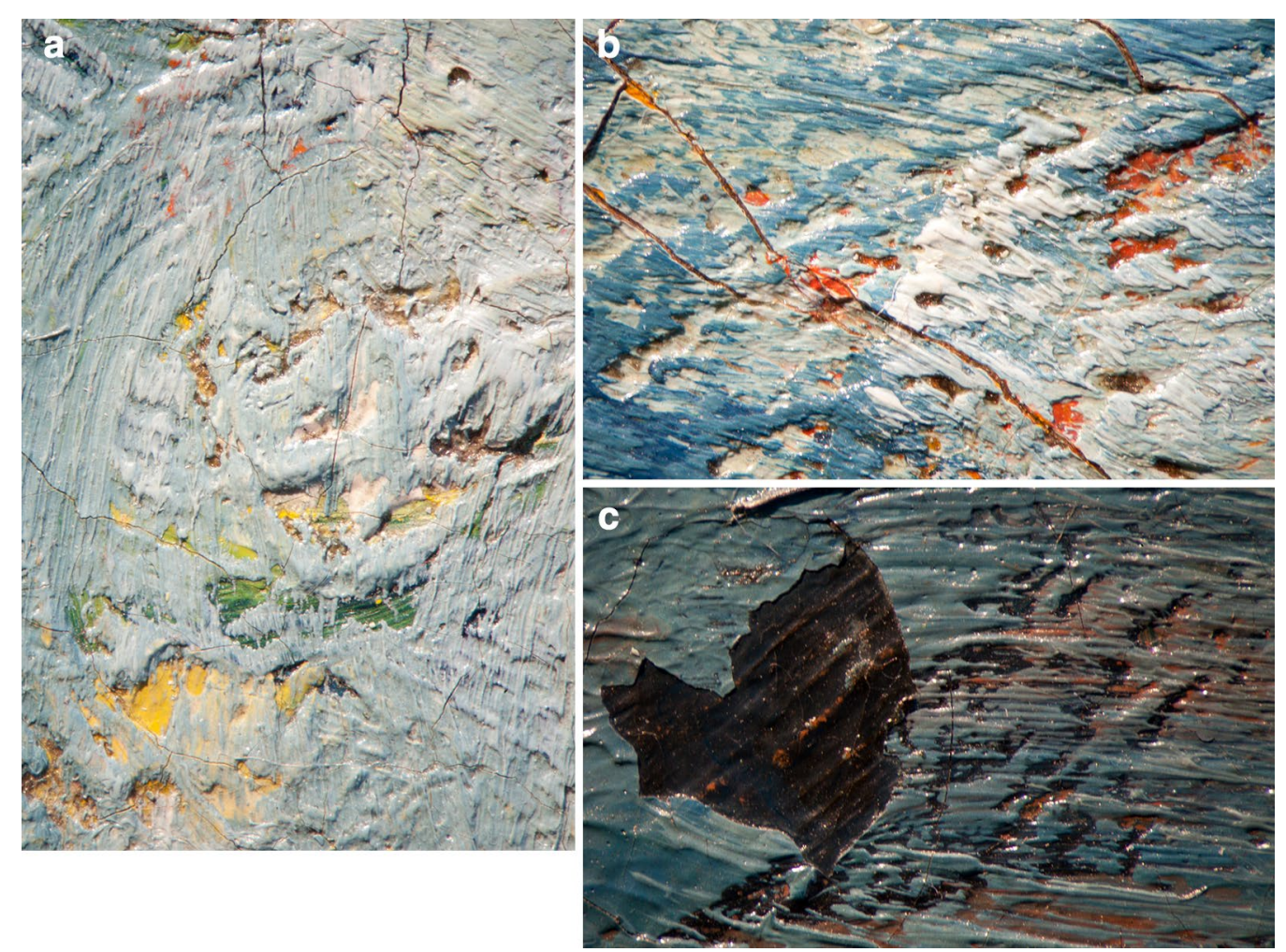

Fig. 3 Details of The Blue Room showing colors from an underlying composition revealed by voids and cracks in surface paint layers. See Fig. 1 for detail locations. a Green, yellow, and red paint visible beneath white near the foot of the bed ( $\times 2.5$ magnification); $\mathbf{b}$ red and yellow seen through voids and cracks in blue and white at the center of the bed ( $\times 3.2$ magnification); c detail of a loss in The Blue Room, in an area of the rug, exposing dark blue underlying paint; dark blue can also be seen through skips in the lighter blue surface brushstrokes ( $\times 4.1$ magnification)

\section{Light microscopy}

All resin-cast cross-sections were examined and digitally photographed using a Nikon Eclipse 80i binocular microscope $(4 \times, 10 \times$ and $20 \times$ objectives with $10 \times$ ocular) equipped with a Nikon Excite 120 mercury lamp for reflected visible and ultraviolet light. The samples were viewed using the Nikon BV-2A cube (excitation 400-440 nm, barrier $470 \mathrm{~nm}$, dichroic mirror $455 \mathrm{~nm}$ ) (violet)/Nikon B-2A cube (excitation 450-490 nm, barrier $520 \mathrm{~nm}$, dichroic mirror $505 \mathrm{~nm}$ ) (blue)/Nikon G-1B cube (excitation band pass $545 / 10 \mathrm{~nm}$, barrier $590 \mathrm{~nm}$, dichroic mirror $575 \mathrm{~nm}$ ) (green). Digital images were taken with the Digital Eclipse DXM 1200 f Nikon Camera in conjunction with the Automatic Camera Tamer (ACT1) control software.

\section{SEM-EDX}

Scanning electron microscopy-energy dispersive X-ray spectroscopy (SEM-EDX) was performed on five resincast cross-sections (X2, X4, X6, X12, and X14; crosssections are illustrated in Additional file 1: Table S1) using the Topcon ABT-60 SEM system (variable pressure mode, $20 \mathrm{kV}$ acceleration voltage for electron beam,
$120 \mu \mathrm{A}$ beam current, $22 \mathrm{~mm}$ stage height) with a Bruker Quantax EDX detector. Images of the cross-sections were captured with back-scattered electron (BSE) imaging using Bruker QUANTAX 200 ESPRIT 1.8.2 software. This software was also used to create elemental maps of elements of interest for each of the cross-sections. A second group of cross-sections (samples X17, X19, and X21) were analyzed on Zeiss Evo MA15 SEM with a Bruker Quantax EDX detector.

\section{uRaman}

Micro-Raman spectroscopy was performed on crosssections using a Renishaw inVia Raman microscope (300 $\mathrm{mW}, 785 \mathrm{~nm}$ diode laser) with a spectral resolution of $3 \mathrm{~cm}^{-1}$ over a spectral range of $100-2500 \mathrm{~cm}^{-1}$. A nominal laser power of $2.5 \mathrm{~mW}$ was used. Analysis of spectra was performed using the WiRE 2.0 software and Thermo OMNIC 8.0.342 software. Material identification is based on known references [19].

\section{$\mu F T-I R$}

Several milligram-sized paint samples were not cast as cross-sections and were instead analyzed in paint flake 
form, in transmission mode, with micro-Fourier transform-infrared (micro-FT-IR) spectroscopy on a Nicolet 6700 FT-IR spectrometer with a Nicolet Contiu $\mu$ m FT-IR microscope (15X IR objective). A spectral range of 4000$650 \mathrm{~cm}^{-1}$ was used with a spectral resolution of $4 \mathrm{~cm}^{-1}$. Each scan is the sum of 128 spectra. The spectra were interpreted using the Thermo OMNIC 8.0.342 software, and material identification based on known references $[20,21]$.

\section{Reflectance imaging spectroscopy (RIS) and luminescence imaging spectroscopy}

Hyperspectral reflectance image cubes were collected with optimized whiskbroom line-scanning imaging spectrometers (Surface Optics Corporation). The first spectrometer utilized an EMCCD detector (Cascade II, Photometrics) operating from 380 to $1000 \mathrm{~nm}$ with $5 \mathrm{~nm}$ sampling, at an illuminance of $1100 \mathrm{~lx}$ and integration time of $50 \mathrm{~ms}$ per line. The second spectrometer utilized an InGaAs array (SUI 640SDV, Sensors Unlimited) operating from 967 to $1680 \mathrm{~nm}$ with $3.4 \mathrm{~nm}$ sampling, $650 \mathrm{~lx}$, and integration time of $100 \mathrm{~ms}$ per line. The image cubes were dark-corrected, flat-fielded, and calibrated to apparent reflectance using diffuse reflectance standards (Labsphere Inc.). The calibrated image cubes were spatially registered using a point-based algorithm [22]. Image processing to find spectral endmembers was done using the commercial software package ENVI. Maps of the various pigments detected were made using the spectral angle mapper algorithm.

Luminescence imaging was carried out to map the use of cadmium yellow in The Blue Room. As previously described [23], a custom illumination and multispectral camera system, operating from 650 to $950 \mathrm{~nm}$, was used to obtain image cubes calibrated to the relative radiance of test panels and paintings. Excitation of the paintings was done using a Kodak Ektagraphic III AT carousel slide projector (OSRAM 300 W EXP bulbs) equipped with F/D $2.5152 \mathrm{~mm}$ Buhl Optical lenses set up at 45 degrees from the normal of the painting. The excitation bandpass was 380-520 nm defined by $50 \mathrm{~mm}^{2}$ Kron/Cousins B astronomy filter. The multispectral camera system consists of a low-noise, 4 megapixel $\mathrm{Si}$ CCD camera (Qimaging Retiga 4000TR) outfitted with a $35 \mathrm{~mm}$ Schneider lens. Spectral interference bandpass filters (FWHM $40 \mathrm{~nm}, 50 \mathrm{~nm}$ spacing, Andover Corp) were used to create the image cube of seven spectral bands. An in-scene calibration method was used to convert the image intensities to relative spectral radiance, using a cadmium pigment target whose spectral emission had been previously measured using the ASD spectroradiometer.

\section{Synchrotron radiation X-ray fluorescence mapping (SR-XRF)}

Synchrotron radiation X-ray fluorescence mapping was performed at the G3 station of the Cornell High Energy Synchrotron Source (CHESS) in Ithaca, NY, using a prototype (model 384B) Maia X-ray detector system. Monochromatic $\mathrm{X}$-rays $\left(\Delta \mathrm{E} / \mathrm{E} \sim 10^{-2}\right)$ were selected using a $\mathrm{W} / \mathrm{B}_{4} \mathrm{C}$ multilayer monochromator, and a beam size of $0.2 \times 0.2 \mathrm{~mm}^{2}$ was selected using motorized slits. The detector was developed jointly at Brookhaven National Laboratory (Upton, NY) and CSIRO (Clayton, VIC, Australia) and is described in detail elsewhere [24, 25]. Previous models of this detector have been successfully applied to elemental mapping of other works of art [26, 27].

To proactively test for the possibility of X-ray induced changes to the painting, prior to performing XRF, one paint sample from The Blue Room was exposed to an approximate dose of $10^{5}$ Grays. Prior studies have found the fading of Prussian blue, the pigment thought most likely to be sensitive to X-rays, to be $10^{8}$ Grays [28]. After irradiation at $10^{5}$ Grays, far above the estimated dose required for XRF mapping, no fading or other effects of the dose could be seen on the sample. As anticipated, the actual dose to the painting during XRF mapping, including both scans (described below), was less than 10 Grays.

An HVAC unit, freezer flaps, portable humidifiers and sensors were installed to maintain and record environmental conditions inside the hutch during the run, and showed that stable temperature and humidity were maintained at $70 \pm 2{ }^{\circ} \mathrm{F}$ and $50 \pm 5 \%$, respectively. The painting was mounted on a motorized, three-axis translation stage to enable automated motion during the scan, and allowing the distance from the painting to detector be carefully controlled. During scanning, the Maia detector was positioned 3-5 $\mathrm{mm}$ from the paint surface. Scans were performed in an "on-the-fly" mode, in which data are collected continuously while the sample moves in a raster-pattern across the incident beam. The integration time per $0.2 \mathrm{~mm}$ pixel was $0.005 \mathrm{~s}$.

Despite the detector's large count rate, the total X-ray intensity available, approximately $10^{12}$ photons/second, was high enough that fluorescence from the painting far exceeded the detector count rate. Aluminum metal was used to reduce the incident beam intensity to approximately $10^{9}$ photons/second, resulting in a typical, total fluorescence count rate at the detector of $4 \times 10^{6}$ photons/second or less.

An incident beam X-ray energy of $12.59 \mathrm{keV}$ was selected for the first scan of the painting. This energy was selected to be sufficiently high to excite fluorescence from the L-lines of mercury $(\mathrm{Hg})$, an elemental component of the pigment vermilion $(\mathrm{HgS})$, but sufficiently low 
to avoid exciting fluorescence from $\mathrm{Pb}$, an expected component of the ground. This energy would also be below the $\mathrm{Pb}$ L3 edge to minimize the X-ray Raman scattering signal. In this configuration, the fluorescence signal was strongly dominated by that of $\mathrm{Zn}$, owing to the use of zinc white as a primary pigment in the palette of both the upper and lower paintings.

In order to eliminate the $\mathrm{Zn}$ fluorescence and so obtain improved maps of lower $\mathrm{Z}$ elements such as $\mathrm{Fe}, \mathrm{Cu}$, and $\mathrm{Mn}$, a second scan of the painting was undertaken at a lower energy, $9.37 \mathrm{keV}$. Approximately the upper twothirds of the picture was successfully scanned in this way, at which point the scan was aborted due to an unplanned interruption to synchrotron operation.

Fluorescence data from the Maia detector were analyzed using the dynamic analysis (DA) method to obtain elemental maps using the software GeoPIXE v6.6 [29]. We make use of the SR-XRF data obtained here to report qualitative elemental distributions, rather than reporting absolute elemental concentrations.

\section{Results and discussion}

The multiple methods described above were employed to provide a better understanding of The Blue Room and the underlying composition. Broad-spectrum IRR (970$1700 \mathrm{~nm}$ ) confirmed but did not give a clear picture of the composition hidden beneath The Blue Room. However, IRR in the $1500-1650 \mathrm{~nm}$ spectral range clearly revealed a portrait of a man in turn-of-the-century Parisian dinner attire, slouched against a cushion or banquette with his head resting on his right hand and rings adorning his fingers (Fig. 4a). Based on the style of the portrait and the handling of the paint, it is hypothesized that the hidden painting is also by Picasso and was also painted in 1901 . The clarity of the IRR image in the $1500-1650 \mathrm{~nm}$ spectral band suggested Prussian blue is the primary blue pigment in the surface composition, as it becomes more transparent around 1300-1500 nm [30]. High resolution IRR subsequently performed in the ranges 1100 $1400 \mathrm{~nm}, 1500-1800 \mathrm{~nm}$, and $2100-2400 \mathrm{~nm}$ provided more detailed images of the hidden painting. The clearly visible texture of brushstrokes, particularly at 2100$2400 \mathrm{~nm}$ (Fig. 4b), strongly suggests that the portrait was a finished work when it was painted over, despite no evidence of a signature. Moreover the distinct and different brush strokes suggest the earlier composition was dry before it was painted over.

Preliminary pXRF analysis was used to guide sampling and for SR-XRF planning. pXRF sites and results are detailed in Additional file 2: Table S2. Paint samples were analyzed using SEM-EDX, $\mu$ FT-IR and $\mu$ Raman spectroscopy to confirm the presence of some pigments and to better understand paint composition, distribution of pigments and fillers, and layering structure in both pictures. Additional file 1: Table S1 summarizes results for all cross-section $(\mathrm{X})$ samples mentioned in the discussion. Additional file 3: Table S3 details $\mu$ Raman data discussed below. Additional file 4: Table S4 provides $\mu$ FT-IR
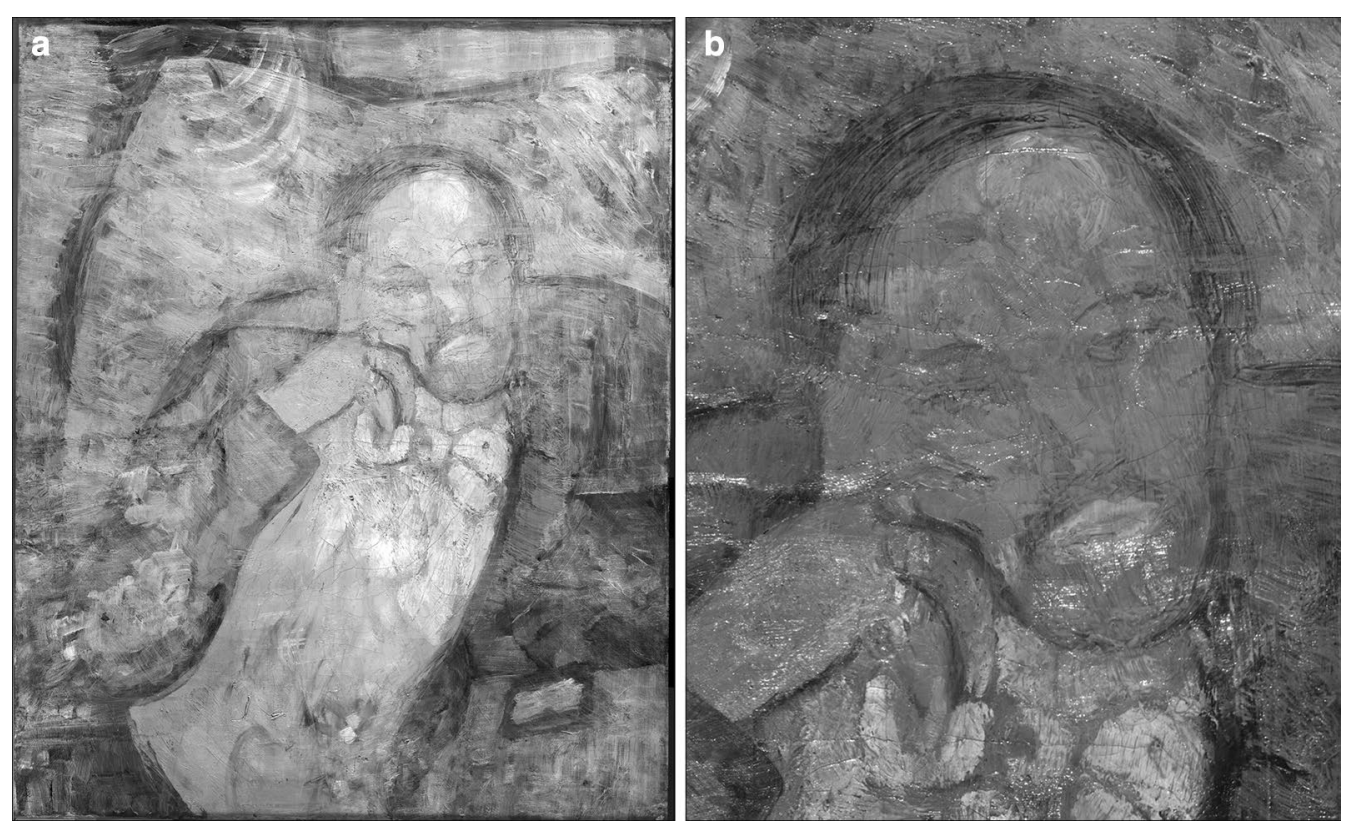

Fig. 4 Filtered IRR images of the entire hidden composition at a 1500-1650 nm and detail at b 2100-2400 nm, with visible brushstroke textures, suggesting the portrait was fully executed before being painted over 
data for pigments identified using this method. Further phase identification on micro-samples and cross-sections with $\mu$ XRPD (micro X-ray powder diffraction) will be examined in future studies. Finally, reflectance imaging spectroscopy (RIS), luminescence imaging spectroscopy, and synchrotron radiation X-ray fluorescence (SR-XRF) elemental mapping were used to identify and qualitatively chart distribution of pigments throughout the two paintings. The success of previous studies using these non-invasive analytical techniques to reveal details of underlying paintings encouraged their use in this study [31-35].

Paint layers vary in thickness between $3.5 \mu \mathrm{m}$ to over $25 \mu \mathrm{m}$, with no highly pastose regions visible. Examination of paint layering structure in cross sections found no evidence of an intermediary ground layer between the two paintings, confirming that The Blue Room was painted directly on top of the hidden portrait. A lack of varnish or dirt between paint layers supports the hypothesis that The Blue Room was painted within a relatively short time after the portrait. With one exception (sample X2; see Additional file 1: Table S1 for discussion), the cross-sectional data show clear stratigraphy and no mixing between upper and lower paint layers. This strongly suggests the underlying painting had time to dry before The Blue Room was painted on top of it. This can be seen in sample X10 taken from the center of the bed (see detail, Fig. 3b), where the border between the buried red/yellow layer and white surface layers is distinct, with no bleeding of the underlying colors into the upper layer. A stunning example of the difference between the two paintings is seen in sample X21, where the layers of the hidden painting are variegated mixtures of yellow, blue, green, and white, mixed wet-into-wet on the canvas. These are topped by a thin, smooth, blue surface layer that is a wellblended mixture with zinc white and Prussian blue. In general, one finds more wet-into-wet mixing in the underlying layers and more blended paint mixtures in the surface layers. These differences are discussed in more detail below, in the section "Picasso's palette and use of color".

The canvas Picasso used was commercially prepared with a uniform white ground consisting of lead white with gypsum filler. In the portrait, paint mixtures appear heterogeneous in photomicrographs as well as the SEMEDX elemental maps, which show pigment distribution. Consistent features of pigment mixtures and morphology between the upper and lower paint layers point to a common paint source for both paintings. The green areas of the SEM-EDX maps, illustrated in Fig. 5d-f, identify a zinc $(\mathrm{Zn})$-rich white pigment being used in both paintings, both on its own and mixed with other pigments. White paint layers of sample X12 (layer 4) and sample X14 (layer 3) contain mostly Zn with larger, distinct barium (Ba) particles or agglomerates (seen as purple in SEM-EDX maps). These are sparsely distributed throughout all layers. It is inferred the $\mathrm{Zn}$-rich white pigment is
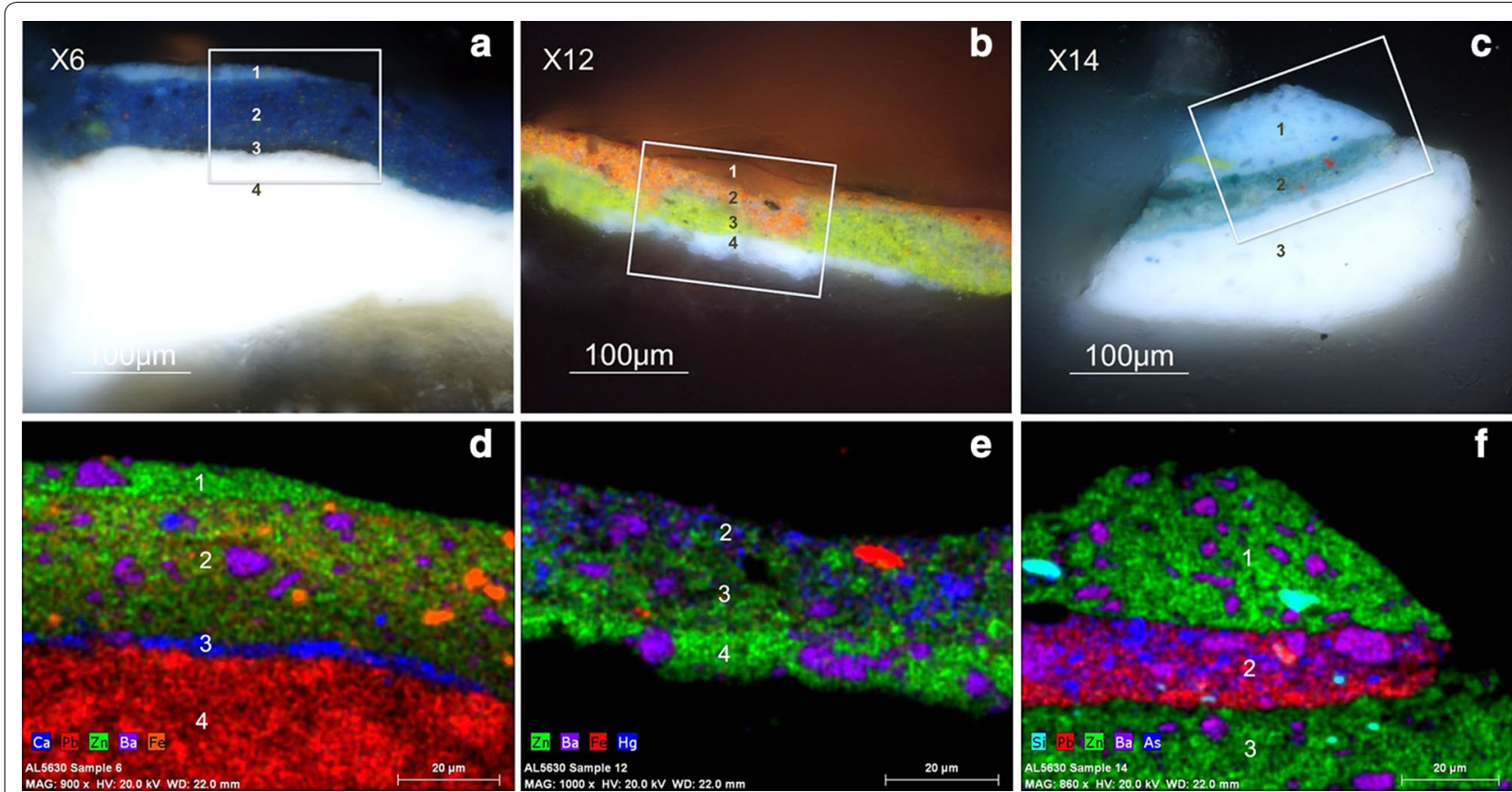

Fig. 5 Samples X6 (a), X12 (b), and X14 (c) with detail EDX elemental maps showing distribution of zinc (green) and barium (magenta). White boxes on cross-sections show area of EDX details (d-fi, respectively). See Additional file 3: Table S3, for corresponding $\mu$-Raman spectra 
a mixture of zinc white (zinc oxide) and barium sulfate $\left(\mathrm{BaSO}_{4}\right)$, a common colorless extender. Peaks at $991 \mathrm{~cm}^{-1}$ in X14, layer 3, and 457,652 , and $990 \mathrm{~cm}^{-1}$ in X12, layer 4, confirm barium sulfate; a peak at $440 \mathrm{~cm}^{-1}$ in X14, layer 3 points to zinc white [19] (see Additional file 3: Table S3, for $\mu$-Raman spectra).

Both $\mathrm{Zn}$ and $\mathrm{Ba}$ are mapped in layer 1 (light blue) of X14; the $\mu$-Raman spectra for this layer also indicates Prussian blue, with peaks at 280, 540, 2096, and $2160 \mathrm{~cm}^{-1}$ [19]. The light blue and medium blue layers of sample X6 (layers 1 and 2, Fig. 5a) are also Zn-rich, with large Ba particles. In addition, iron (Fe) particles (orange areas in the EDX map, Fig. 5d), which indicate Prussian blue, are also dispersed within the $\mathrm{Zn}$ (green) matrix. Only one or two Fe particles are detected in layer 1, while layer 2 is a more even mixture of $\mathrm{Fe}$ and $\mathrm{Zn}$ particles. The similarities seen between these blue paint layers suggest Picasso mixed Prussian blue, a strongly tinting pigment, and zinc white to achieve the variety of blue tones seen in The Blue Room.

Varying amounts of this same $\mathrm{Zn} / \mathrm{Ba}$ mixture are found in all paint layers shown in Fig. 5 except lead (Pb)-rich (red) layers in samples X6 (layer 4) and X14 (layer 2). In sample X12 (Fig. 5b and e), Zn (green) and Ba (purple) particles are seen with SEM-EDX in all layers. In the light red layer (layer 2), an almost even ratio of $\mathrm{Zn}$ (green) particles mixed with $\mathrm{Hg}$ (blue) particles indicate a mixture of vermilion red $(\mathrm{HgS})$ and zinc white. The continuity of $\mathrm{Zn} / \mathrm{Ba}$ mixtures in both upper and lower paint layers suggests the same brand of zinc white paint with barium sulfate filler may have been used in both pictures.

Similarly, small red particles are found evenly distributed throughout both surface and buried paint layers containing Prussian blue, such as in the topmost layer of light blue paint, from The Blue Room, in sample X7, and the darker blue layer directly beneath it, from the hidden portrait (Fig. 6a). Peaks at 254, 284, and $345 \mathrm{~cm}^{-1}$ in the $\mu$-Raman spectra (Fig. $6 \mathrm{~b}$ and c) of these layers identify these particles as the red pigment vermillion [19]. Similar mixtures of Prussian blue with vermilion are found in other samples as well, such as $\mathrm{X} 1, \mathrm{X} 2$, and $\mathrm{X} 6$, in both The Blue Room and the hidden portrait. The small amount, scale, and even distribution of vermilion particles within layers containing Prussian blue suggest the red pigment was added by the paint manufacturer. In the early twentieth century, Prussian blue was one of the least expensive blue pigments, and blue paints containing Prussian blue were sold by paint manufacturers under a variety of names and in a variety of hues [36].

\section{Picasso's palette and use of color}

Pigment identification is based on combined information from pXRF spot analysis and microanalysis of paint samples. Additional file 1: Table S1 summarizes findings for cross-section samples mentioned in the text, Additional file 2: Table S2 details pXRF results, Additional file 3: Table S3 details $\mu$ Raman data discussed below, and Additional file 4: Table S4 provides $\mu$ FT-IR data for pigments identified using this method.

Table 1, below, compares and illustrates the similarity of Picasso's palette in The Blue Room and the hidden portrait. It lists the principal pigments (in italics) identified in each picture along with less-prevalent pigments and fillers. For reference, common chemical formulas for each pigment are provided; further discussion about specific pigments is found in the sections below.

Additional knowledge about pigment distribution on a macroscale comes from SR-XRF and RIS mapping. SRXRF and RIS pigment distribution maps, seen in Figs. 7 and 8 , respectively, provide clues not only about Picasso's palette for the two works, but also illustrate how he used his colors differently in each painting. Endmember and reference spectra associated with the RIS maps are shown in Fig. 9.

Table 1 Summary of pigments and other materials used in The Blue Room and in the hidden portrait

\begin{tabular}{|c|c|c|}
\hline & The Blue Room & Portrait \\
\hline Ground $^{f}$ & \multicolumn{2}{|l|}{$\begin{array}{l}\text { Lead white }\left(2 \mathrm{PbCO}_{3} \cdot \mathrm{Pb}(\mathrm{OH})_{2}\right)^{\mathrm{a}, \mathrm{b}, \mathrm{d}} \\
\text { with gypsum }\left(\mathrm{CaSO}_{4} \cdot 2 \mathrm{H}_{2} \mathrm{O}\right)^{2} \text { filler }\end{array}$} \\
\hline Fillers & \multicolumn{2}{|l|}{$\begin{array}{l}\text { Barium white }\left(\mathrm{BaSO}_{4}\right)^{\mathrm{a}, \mathrm{b}, \mathrm{c}, \mathrm{d}} \text {; } \\
\text { silica (quartz) }\left(\mathrm{SiO}_{2}\right)^{\mathrm{a}}\end{array}$} \\
\hline Blue & \multirow[t]{2}{*}{$\begin{array}{l}\text { Prussian blue }\left(\mathrm{Fe}_{4}\left[\mathrm{Fe}(\mathrm{CN})_{6}\right]_{3}\right)^{\mathrm{a}, \mathrm{b}, \mathrm{d}} \\
\text { Ultramarine (synth.) }\left(\mathrm{Na}_{6-}\right. \\
\left.{ }_{10} \mathrm{Al}_{6} \mathrm{Si}_{6} \mathrm{O}_{24} \mathrm{~S}_{2-4}\right)^{\mathrm{b}, \mathrm{e}}\end{array}$} & $\begin{array}{l}\text { Prussian blue } \\
\qquad\left(\mathrm{Fe}_{4}\left[\mathrm{Fe}(\mathrm{CN})_{6}\right]_{3}\right)^{\mathrm{a}, \mathrm{b}, \mathrm{d}}\end{array}$ \\
\hline Black & & $\begin{array}{l}\text { Carbon black }(\mathrm{C})^{\mathrm{b}} \\
\text { Bone black }\left(\mathrm{C}+\mathrm{Ca}_{3}\left(\mathrm{PO}_{4}\right)_{2}\right)^{\mathrm{a}}\end{array}$ \\
\hline White & Zinc white $(Z n O)^{a, b, d}$ & $\begin{array}{l}\text { Zinc white }(\mathrm{ZnO})^{\mathrm{a}, \mathrm{b}, \mathrm{d}} \\
\text { Lead white }\left(2 \mathrm{PbCO}_{3} \cdot \mathrm{Pb}(\mathrm{OH})_{2}\right)^{\mathrm{e}}\end{array}$ \\
\hline Green & $\begin{array}{l}\text { Emerald green } \\
\left(3 \mathrm{Cu}\left(\mathrm{AsO}_{2}\right)_{2} \cdot \mathrm{Cu}\left(\mathrm{CH}_{3} \mathrm{COO}\right)_{2}\right)^{\mathrm{a}, \mathrm{d}} \\
\text { Viridian }\left(\mathrm{Cr}_{2} \mathrm{O}_{3} \cdot 2 \mathrm{H}_{2} \mathrm{O}\right)^{\mathrm{a}, \mathrm{d}, \mathrm{e}}\end{array}$ & $\begin{array}{l}\text { Compound green-chrome } \\
\text { or cadmium yellow mixed } \\
\text { with Prussian blue and } \\
\text { bone black }\end{array}$ \\
\hline Yellow & $\begin{array}{l}\text { Chrome yellow }\left(\mathrm{PbCrO}_{4}\right)^{\mathrm{a}, \mathrm{b}, \mathrm{c}, \mathrm{d}} \\
\text { Cadmium yellow }(\mathrm{CdS})^{\mathrm{a}, \mathrm{b}, \mathrm{d}}\end{array}$ & Chrome yellow $\left(\mathrm{PbCrO}_{4}\right)^{\mathrm{a}, \mathrm{b}, \mathrm{c}, \mathrm{d}}$ \\
\hline Red & Vermilion $(\mathrm{HgS})^{a, b, d}$ & \\
\hline Other & $\begin{array}{l}\text { Acrylic resin varnish (from later } \\
\text { conservation treatment) }\end{array}$ & \\
\hline \multicolumn{3}{|c|}{$\begin{array}{l}\text { Principal pigments are italicized. Common chemical formulas are provided for } \\
\text { reference }\end{array}$} \\
\hline \multicolumn{3}{|c|}{ a SEM-EDX } \\
\hline \multicolumn{3}{|c|}{ b $\mu$ Raman } \\
\hline \multicolumn{3}{|l|}{${ }^{c} \mu \mathrm{FT}-\mathrm{IR}$} \\
\hline \multicolumn{3}{|l|}{${ }^{d}$ XRF } \\
\hline \multicolumn{3}{|l|}{ e RIS } \\
\hline f Comme & ially prepared canvas & \\
\hline
\end{tabular}



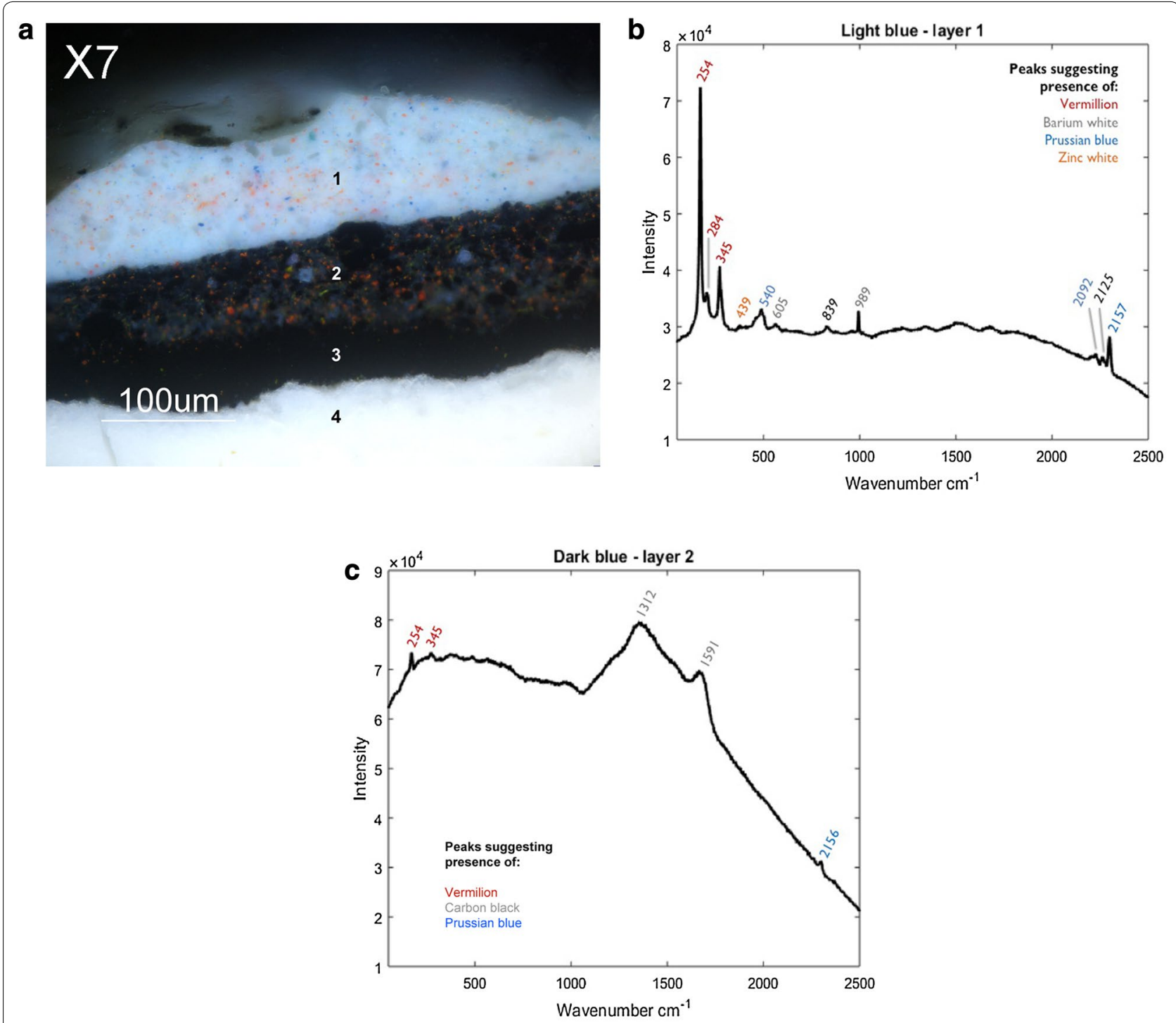

Fig. 6 a Red particles are visible scattered throughout layers 1 (light blue) and 2 (dark blue) of sample X7. Micro-Raman spectra for $\mathbf{b}$ the dark blue and $\mathbf{c}$ light blue paint layers of sample X7 identify these red particles as the red pigment vermilion

\section{Blue}

Prussian blue is the primary blue pigment in both paintings. As stated above, very small amounts of vermilion red were found uniformly mixed into all Prussian hues. Chrome or cadmium yellow particles are also found mixed into Prussian blue paint in some samples (sample $\mathrm{X} 2$, X14). In the hidden portrait, Prussian blue is mixed with a carbon-based black (see, for example, sample X7, layer 2). The dark blue color resulting from the mixture can be seen where a loss in the surface paint layers exposes the underlying paint near the sitter's right elbow (see detail, Fig. 3c). Carbon-based black, mixed with Prussian blue in sample X4 and used pure in sample X6, layer 3, was identified as bone black due to the detection of calcium and phosphorus by SEM-EDX analysis. In another sample-X1, layer $6-\mu \mathrm{FT}$-IR spectra identifies barium sulfate mixed with black (see Additional file 4: Table S4). A small but sharp peak around $985 \mathrm{~cm}^{-1}$ is indicative of barium sulfate, although the combination of pigments appears to create a broad peak from 1250 to $900 \mathrm{~cm}^{-1}$ which masks adjacent barium sulfate peaks. While corresponding peaks at $\sim 1100 \mathrm{~cm}^{-1}$ and between $\sim 1400$ and $1750 \mathrm{~cm}^{-1}$ in the sample suggest bone black, a smaller peak at $\sim 2150 \mathrm{~cm}^{-1}$ is shifted too far from the standard for a positive assignment in this sample. 

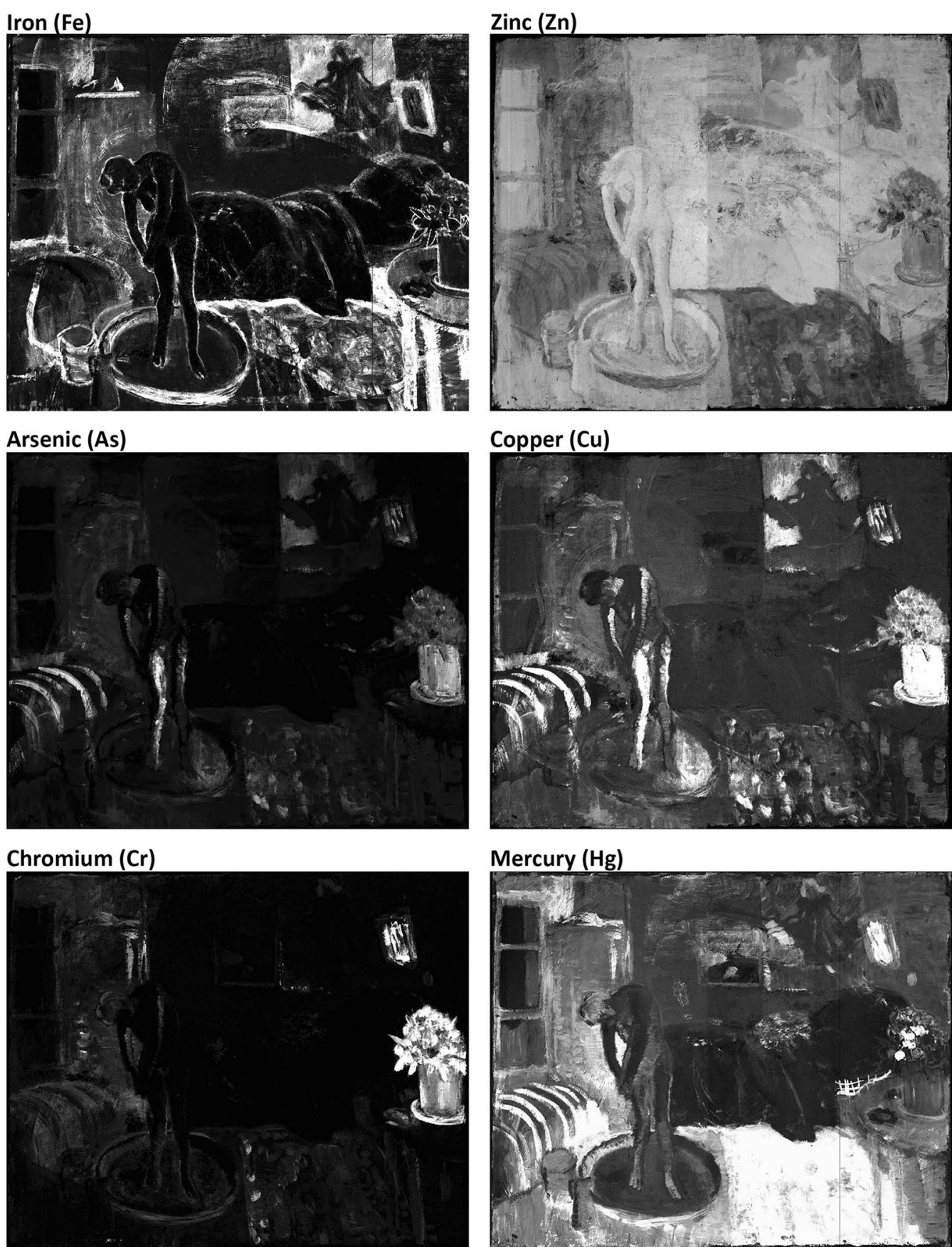

Mercury ( $\mathrm{Hg})$

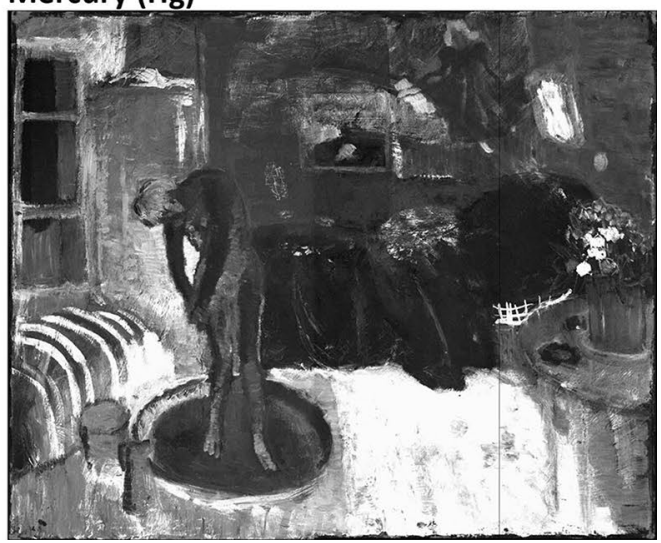

Fig. 7 Synchrotron radiation X-ray fluorescence (SR-XRF) elemental maps for iron, zinc, arsenic, copper, chromium, and mercury. Lighter areas indicate a higher concentration of the element being mapped

Dark areas of the XRF map for iron (Fe) indicate where one might expect to find Prussian blue in the portrait, such as the sitter's jacket (his right arm and left shoulder), the bold outlines of the cushion behind his head, the contours of his hair, and fine lines defining his hand, bow tie, and facial features. Because the blue is mixed with carbon-based black, which strongly absorbs infrared wavelengths, these features show up clearly in the filtered near-IR images (Fig. 4a). However, these lines fail to register in the RIS map for Prussian blue because the black in the mixture shifts the spectra away from the characteristic reflectance of pure Prussian blue. 

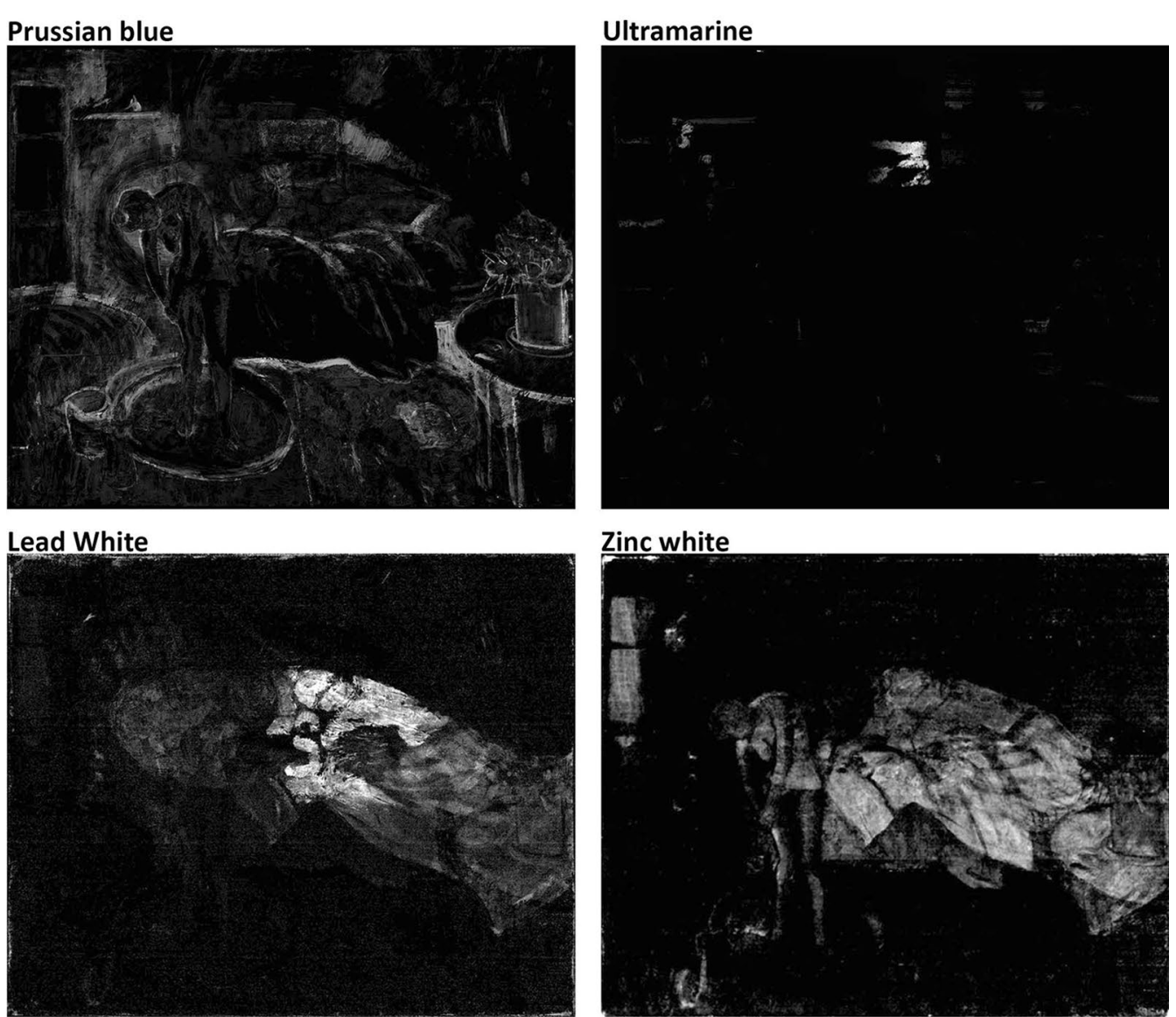

\section{Zinc white}

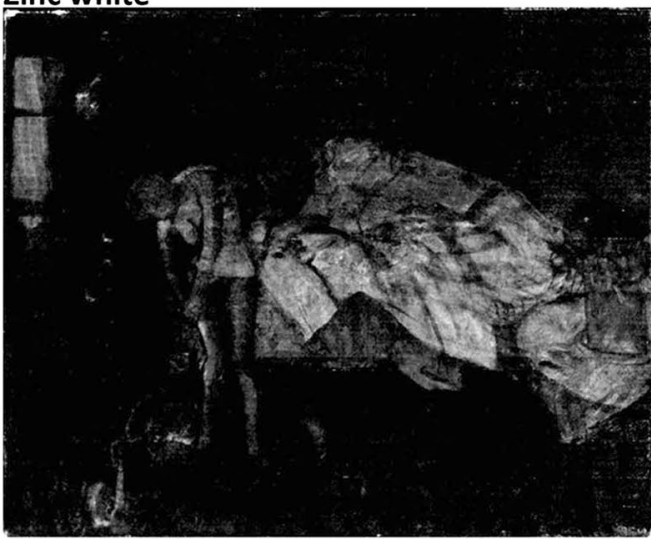

\section{Viridian}

\section{Vermilion}
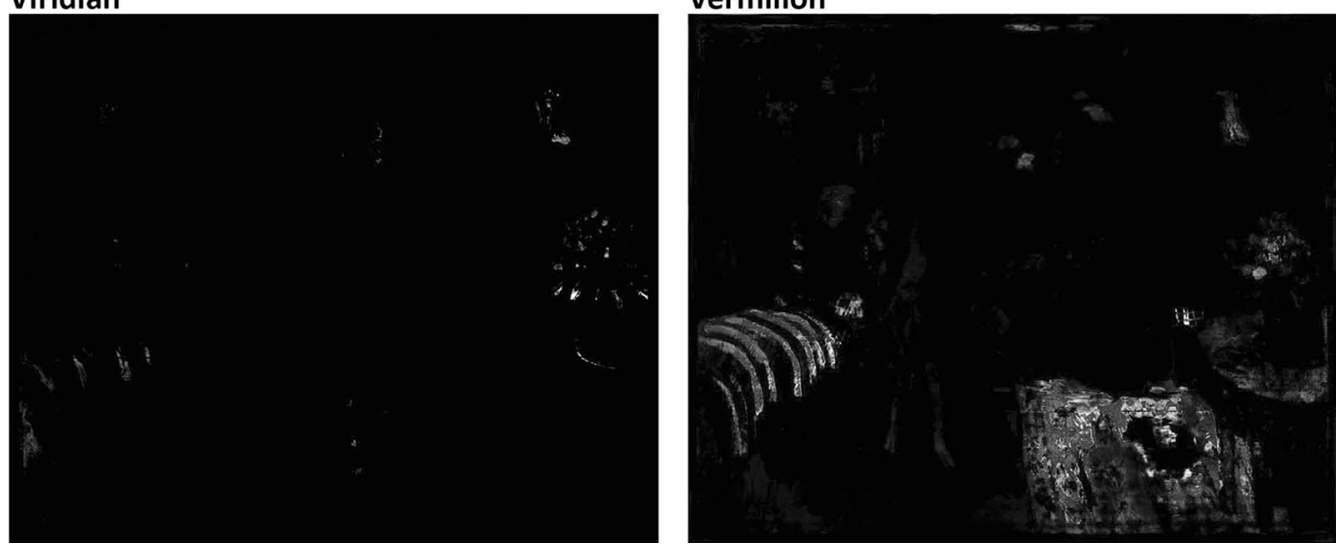

Fig. 8 Reflectance imaging spectroscopy (RIS) maps for Prussian blue, ultramarine blue, lead white, zinc white, viridian green, and vermilion red. Lighter areas show where the reflectance spectrum of the pigment in question can be detected

Ultramarine blue is challenging to identify with XRF techniques due to beam attenuation of the low-energy fluorescence of the lighter elements in air. Analysis of the RIS image cube, however, revealed spectra consistent with ultramarine blue with a strong absorption at $600 \mathrm{~nm}$ with a transition to high reflectance at $\sim 700 \mathrm{~nm}$ (see Fig. 9). The hyperspectral map for ultramarine blue shows Picasso selectively used this pigment in The Blue Room for the sea in the small Mediterranean seascape (thought to be a representation of one of his own paintings) on the back wall of the studio [5]. 


\section{RIS Reference spectra}

\section{Prussian Blue}

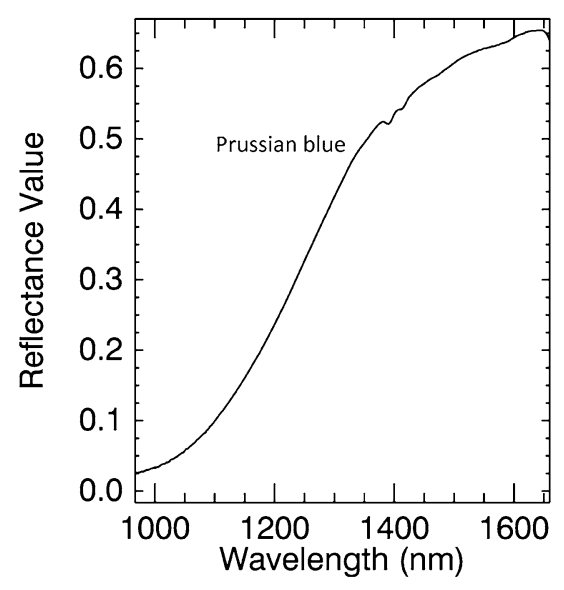

Lead White and Zinc white

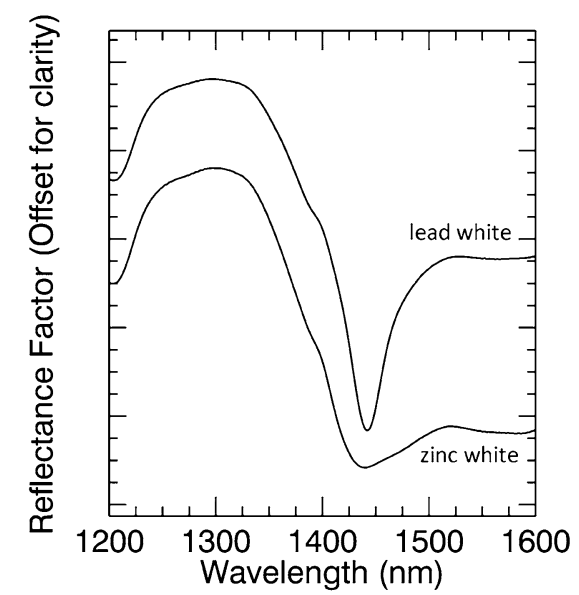

Ultramarine, Vermilion, and Viridian

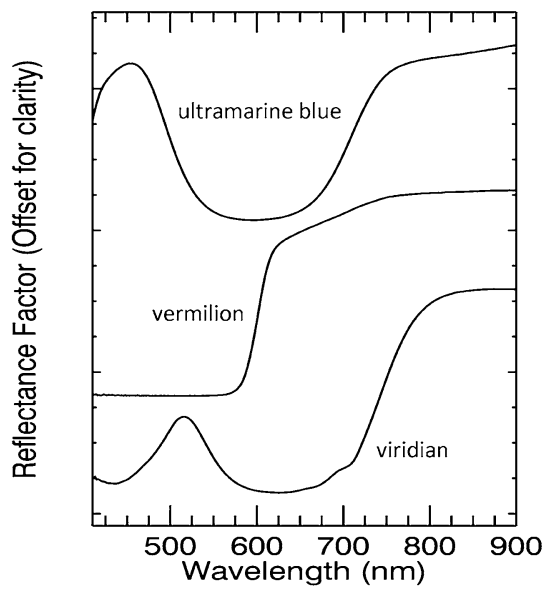

RIS Endmember spectra
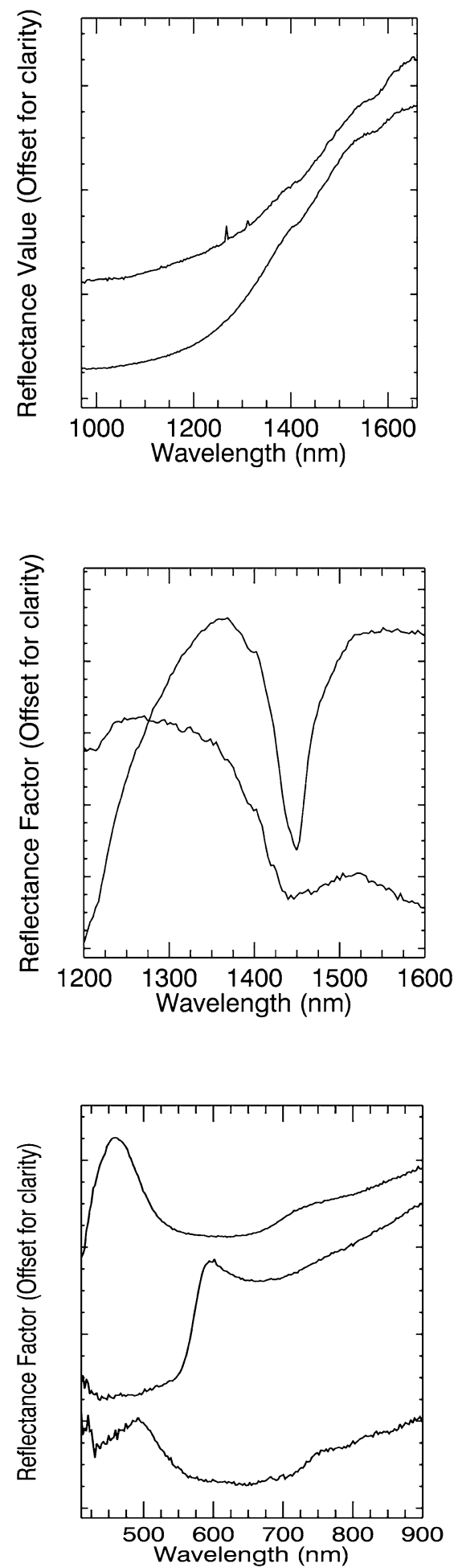

Fig. 9 Endmember and reference reflectance spectra corresponding to Prussian blue, zinc white and lead white, and ultramarine blue, vermilion red, and viridian green 


\section{White}

In both The Blue Room and the portrait, zinc white appears to be the primary white pigment. It is used in the windows, the bed sheets, and in the bathing figure, and mixed primarily with Prussian blue throughout the upper paint layers. No lead white pigment was found in The Blue Room. The only instance of lead white used outside of the ground occurs in the portrait, where the RIS map reveals Picasso's selective use of lead white for the sitter's bow tie and areas of the shirt directly below the tie. This was determined from a narrow absorption feature at $1447 \mathrm{~nm}$ attributed to the hydroxyl group of hydro-cerussite (see Fig. 9). In the rest of the shirt and in the sitter's hand, zinc white was used instead. The RIS map for zinc white is complicated by the presence of the pigment in both paint layers; however, cross-sectional analysis finds zinc in the layer corresponding to the sitter's shirt, such as the white layer of sample X14.

While both zinc and barium are both present in white paint layers, the barium exists as large discrete particles and not as an intimate co-precipitate with the zinc, as would be expected for the presence of lithopone, which is $\mathrm{ZnS}$ co-precipitated with $\mathrm{BaSO}_{4}$ rather than $\mathrm{ZnO}$. Furthermore, the Raman spectra collected in the white paint layers do not show evidence of lithopone peaks. Barium white has Raman bands at 453, 461, 616, 647, and $988 \mathrm{~cm}^{-1}$. Zinc white has Raman bands at 331,383 , and $438 \mathrm{~cm}^{-1}$. Lithopone has bands at 216,276, and $342 \mathrm{~cm}^{-1}$ that were not observed in the white paint spectra. As a result, both from a morphological and spectroscopic perspective, lithopone is not present in the white paints of The Blue Room.

\section{Yellow}

Visual examination and SR-XRF mapping suggested chrome yellow is the principal pigment used for the cushion behind the sitter in the portrait. This was confirmed via microanalysis of underlying yellow layers in sample
X5, taken from the top edge of The Blue Room in the area of the cushion. The pigment is also found mixed with red in sample X10 in the center of the sitter's shirt, below the bowtie. In The Blue Room, chrome yellow is used for May Milton's hair in the Toulouse-Lautrec poster and for highlights in the hair of the bathing figure.

Agreement between the near infrared luminescence image originating from deep trap states in cadmium based pigments $(\mathrm{Cd} / \mathrm{Zn} / \mathrm{Se} / \mathrm{S})$ (Fig. 10a) and the cadmium (Cd) SR-XRF elemental map (Fig. 10b) suggests that cadmium yellow was the primary yellow used for the bathing figure's hair and for the rocks in the seascape painting on the back wall of the studio. Cadmium yellow also appears to contribute to the brown color of the circular tabletop and the table legs at right.

Cadmium yellow pigments commonly exist as solid solutions where zinc, mercury, or selenium substitutions can be used to change the pigment's hue. Yellow cadmium sulfides most frequently occur as a solid solution with zinc sulfide as $\mathrm{Cd}_{(1-\mathrm{x})} \mathrm{Zn}_{\mathrm{x}} \mathrm{S}$ [37]. Micro-Raman spectroscopy has been used to identify these solid solutions, which can have implications about the pigment's stability. The poorly crystalline nature of the cadmium yellow pigments in this work, and the fluorescence of the oil binder led to cadmium yellow pigments being inferred by the presence of cadmium in yellow regions (SEM-EDX and XRF mapping) and the pigment's characteristic infrared luminescence. Further work by $\mu \mathrm{XPD}$ could be used to determine the lattice parameters indicating the degree of Zn substitution into the crystal lattice.

Similarly, chrome yellow exists in solid solutions ranging from $\mathrm{PbCrO}_{4}$ to $\mathrm{PbCr}_{1-\mathrm{x}} \mathrm{S}_{\mathrm{x}} \mathrm{O}_{4}$. These phases can be identified using $\mu$ Raman spectroscopy and $\mu$ XPD [38, 39]. The chromate stretching band at $841 \mathrm{~cm}^{-1}$ increases as the amount of sulfate in the pigment increases, along with changes in the intensities of the chromate bending modes. The sulfate band similarly shifts from 971
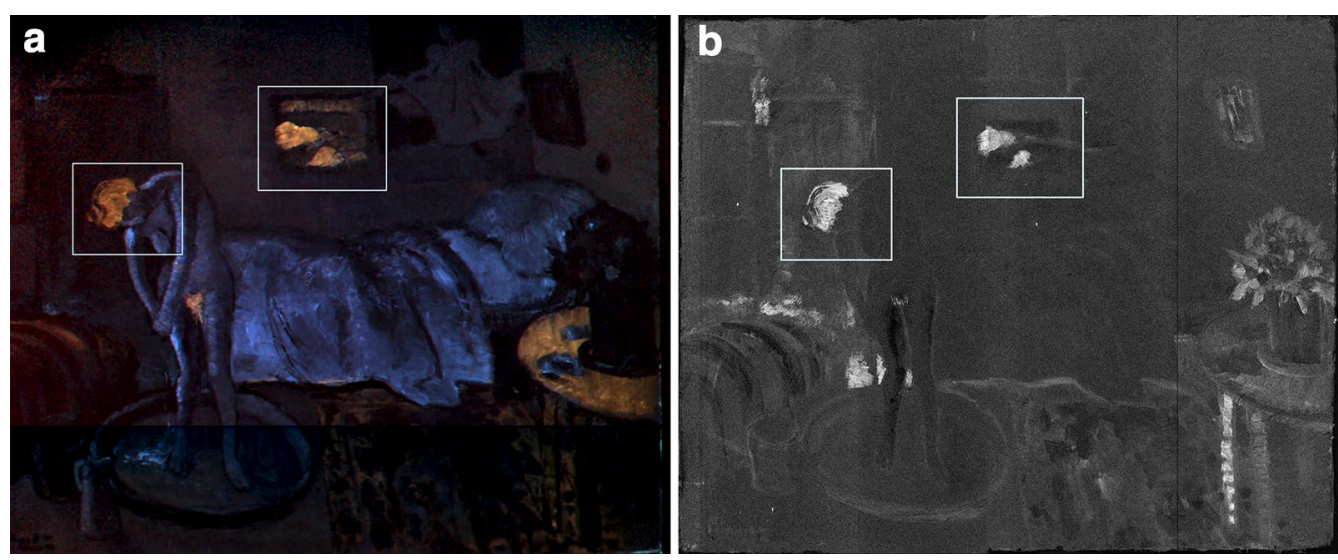

Fig. 10 Areas of overlap between a Luminescence imaging $(750-850 \mathrm{~nm})$ of cadmium yellow (CdS) and $\mathbf{b}$ SR-XRF mapping of cadmium (Cd) 
to $980 \mathrm{~cm}^{-1}$ as the sulfate component of the pigment increases. Chrome yellow pigments were identified in three of the paint cross-sections studied by $\mu$ Raman spectroscopy, X3, X4, and X5 (Fig. 11). In sample X5 a sulfate band was identified at $973 \mathrm{~cm}^{-1}$, which is consistent with the chromate stretching band in this sample being shifted to $846 \mathrm{~cm}^{-1}$. Sample X3 has a sulfate band at $978 \mathrm{~cm}^{-1}$, and also a chromate band at $846 \mathrm{~cm}^{-1}$, also consistent with a $\mathrm{PbCr}_{1-\mathrm{x}} \mathrm{S}_{\mathrm{x}} \mathrm{O}_{4}$ formulation (this, in addition to the presence of barium sulfate in the sample, may also account for a larger peak in the $\mu \mathrm{FT}$-IR spectra at $\sim 1050 \mathrm{~cm}^{-1}$; see Additional file 4: Table S4). Sample $\mathrm{X} 4$, however, has no visible sulfate bands, and chromate stretching bands between 842 and $844 \mathrm{~cm}^{-1}$. As a result, it can be ascertained that Picasso used two different shades of chrome yellow, with the sulfate-rich shade being a paler form of the pigment.

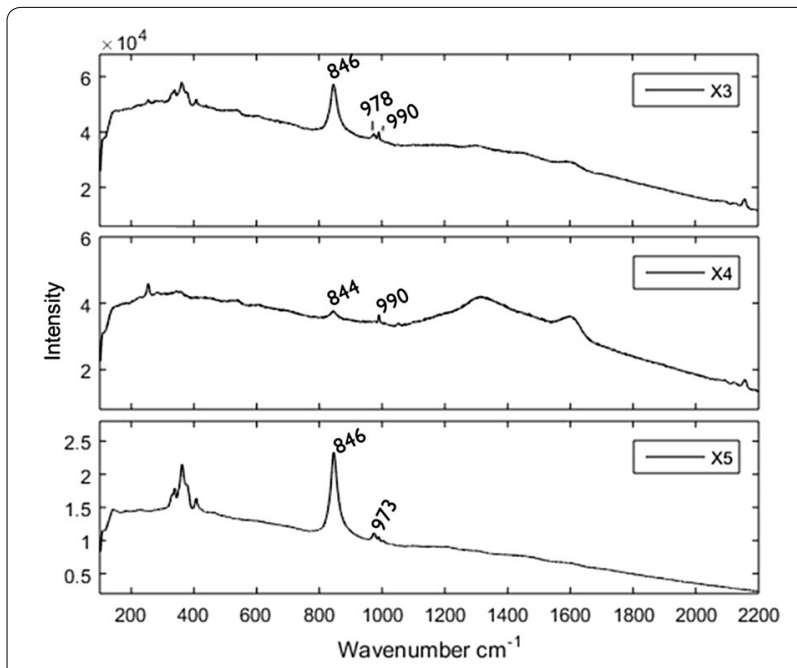

Fig. $11 \mu$ Raman spectra detailing sulfate bands $\left(973,978 \mathrm{~cm}^{-1}\right)$ and chromate stretching bands ( 846 and $842-844 \mathrm{~cm}^{-1}$ ) for chrome yellow in samples $\times 3, \times 4$, and $\times 5$
Scanning electron microscopy-energy dispersive X-ray spectroscopy analysis suggests chrome yellow is also mixed with cadmium yellow in the yellow layer of sample $\mathrm{X} 12$, taken from the edge of the striped sofa under the window in The Blue Room. In the EDX map, chromium $(\mathrm{Cr})$ is mapped in the yellow layer as orange (Fig. 12b) and cadmium $(\mathrm{Cd})$ is mapped in the same layer as red (Fig. 12c). However, it is unclear whether this layer corresponds with the yellow in the sofa (a yellow stripe covered by a red stripe) or comes from the underlying composition. The bottom layer is identified as zinc white mixed with barium sulfate.

\section{Green}

In the portrait, microanalysis found mainly compound greens, blended mixtures of ivory black and chrome yellow with some Prussian blue. These mixtures can be seen in layer 2 of sample X3 and layer 3 of sample X19, both taken from the background along the top edge of the portrait. The difference in size of the chrome yellow and ivory black pigment particles and mixture of pigments present elsewhere as pure color suggest color mixed on the artist's palette rather than a commercial mixture. The appearance may have been similar to the unevenlyblended green background of Picasso's Woman in Blue (Museo Nacional Centro de Arte, Reina Sofia), painted in Madrid in the spring of 1901. This is an exception to the pure color or wet-into-wet mixing generally seen in the underlying paint layers; for example, see sample $\mathrm{X} 20$, taken from an area of the portrait where the edge of the sitter's jacket meets the yellow cushion behind him. Streaks of blue (mixed with large black pigment particles) and yellow in layer 2 indicate mixing of adjacent colors directly on the canvas, rather than blending on the palette.

Picasso's use of copper acetoarsenite, or emerald green, in The Blue Room is illustrated by the SR-XRF maps for copper $(\mathrm{Cu})$ and arsenic (As) (Fig. 7). The maps overlap
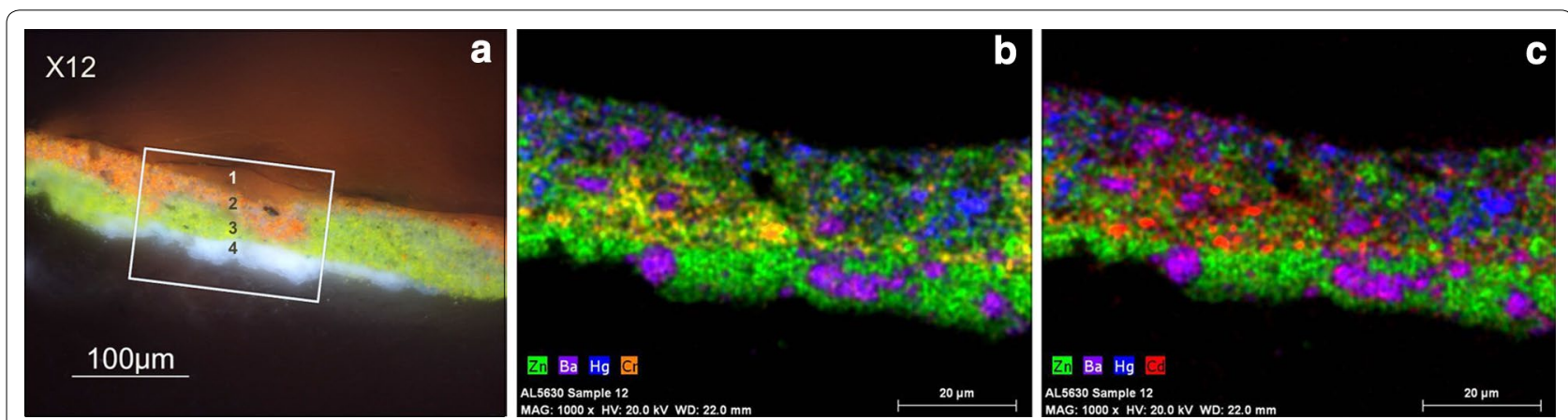

Fig. 12 a Sample X12 with area of EDX map indicated. b EDX map with chromium (Cr) mapped in orange. c EDX map with cadmium (Cd) mapped in red 
strongly, indicating that Picasso used emerald green in the light green stripes of the sofa and the highlights on the legs of the bathing figure in The Blue Room. Emerald green is also used in the small painting above the vase of flowers. When the $\mathrm{Cu}$ and As maps are compared with the Fe SR-XRF map, a mixture of emerald green and Prussian blue in the background of the Toulouse-Lautrec poster and in the undertone for the bouquet of flowers is indicated (Fig. 7). This mixture is also suggested for the brown wardrobe behind the central figure; however, a thick green layer (layer 2) under a blue surface layer in sample X17, taken from the background just above the bathing figure's shoulder, suggests there may alternately be an unidentified aspect of the hidden painting or Picasso's process in this area.

Finally, in a few green areas of The Blue Room, chromium is strongly indicated by the brightest-or most highly concentrated-regions of the SR-XRF elemental map (Fig. 13a), specifically the leaves at the base of the bouquet of flowers and areas of the small painting above the head of the bed. These areas overlap with the brightest regions of the RIS map for viridian, a hydrated version of chromium oxide (Fig. 13b). RIS analysis of the image cube revealed green spectra having a shoulder at $650 \mathrm{~nm}$ and a sharp transition at $\sim 750 \mathrm{~nm}$ consistent with viridian green (Fig. 9). The overlap between the RIS and SRXRF maps shows Picasso's highly selective use of viridian in The Blue Room.

\section{Red}

Vermilion is the only red pigment found in either painting. In The Blue Room, pure vermilion is used primarily as an accent in the sofa, rug, and flowers. It is also blended with zinc white in the pink tones of the bathing figure's torso and May Milton's skirt, rather than the more expected use of a lake pigment in these regions. RIS analysis was used to assign vermilion based upon spectra having a sharp transition edge at $\sim 590 \mathrm{~nm}$ (Fig. 9).

Red paint in the portrait is visible in a few areas through the surface layers of The Blue Room, such as below the signature at lower left and in the center, near the foot of the bed. In these and other areas, the mercury (Hg) elemental map (Fig. 14) faintly indicates the use of vermilion for (a) a region in the background of the portrait at upper left; (b) for the sitter's lips and fingertips; (c) the lapel of his jacket; and (d) for an oval shape in a region of the man's shirt, which appears white overall in the infrared reflectograms.

The oval shape on the front of the man's shirt corresponds with the center of the bed in The Blue Room. Here, both red and yellow paint are visible beneath the surface paint layers (see details, Figs. 3b, 15a). Sample $\mathrm{X} 10$ taken from this area reveals a relatively thick, variegated layer of vermilion and chrome yellow, mixed wet-into-wet, beneath white and blue layers of the surface composition. In this same area, in the RIS map for lead white, one observes a distinct void indicating an absence of white. When compared with the original infrared image (Fig. 4a), a shape corresponding to this void becomes clear. The handling of paint in this area revealed with high-resolution IRR (see detail, Fig. 15b) recalls the flowers in Picasso's Peonies (National Gallery of Art, Washington), painted in Paris in early summer of 1901. However, instead of pink or white, as in Peonies, the 'flower' in The Blue Room's hidden portrait is primarily red. Figure 16 shows a colorized estimation of the area created in Photoshop. The Hg and Cr SR-XRF maps were registered with the IRR image. Areas of interest in the $\mathrm{Hg}$ and $\mathrm{Cr}$ SR-XRF maps were selected and converted to red and yellow, respectively. The colorized layers were superimposed on the IRR image to visualize color in the area of the flower.
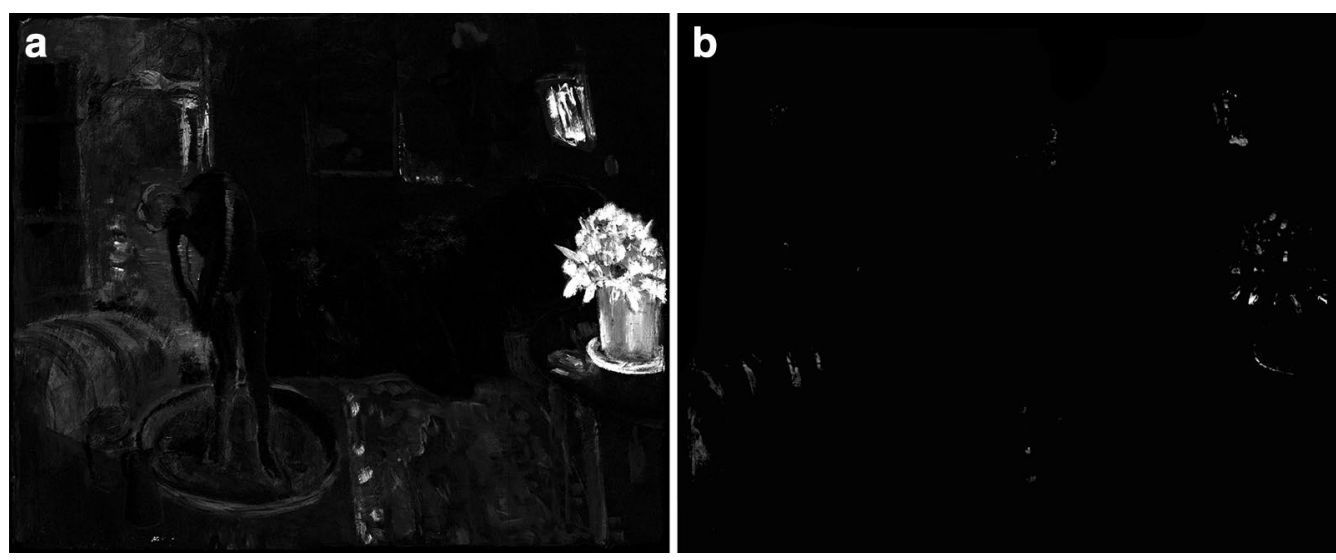

Fig. 13 Direct comparison between a SR-XRF map for Cr and $\mathbf{b}$ RIS map for viridian 


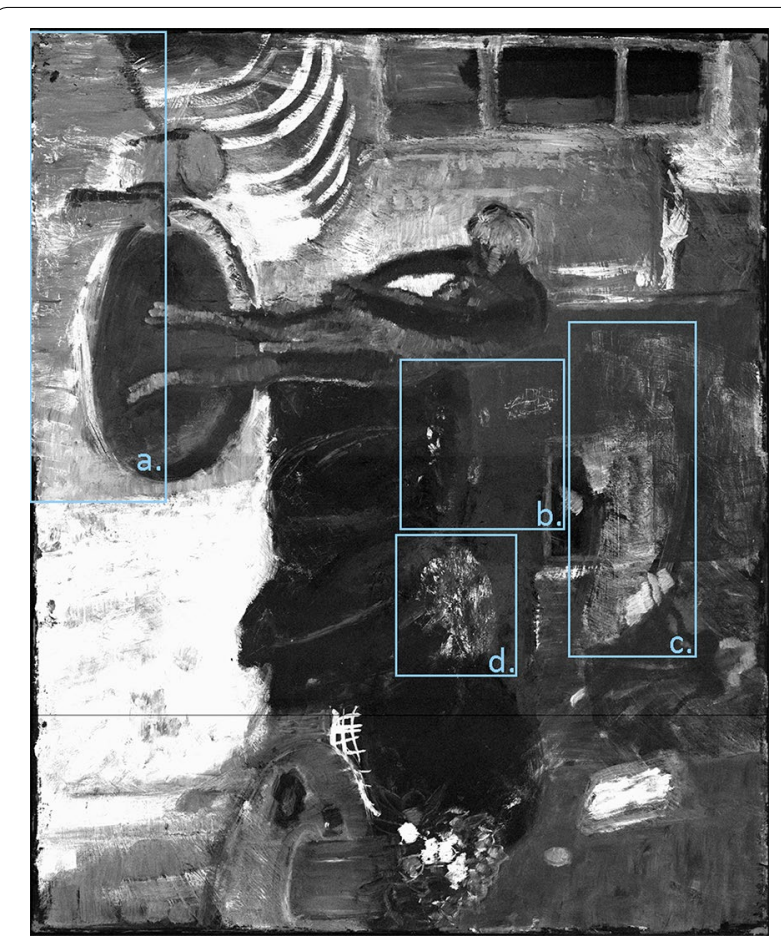

Fig. 14 SR-XRF mercury $(\mathrm{Hg})$ map. Areas of vermilion in the hidden portrait are outlined in blue

\section{Conclusions}

The tandem use of microanalytical methods, SR-XRF, and RIS revealed important information about The Blue Room and the untitled portrait beneath it that would have been inaccessible to any one of the single techniques described above. In the case of these two paintings, no individual technique could completely characterize Picasso's palette or completely reconstruct the underlying portrait.

Sampling and microanalysis were necessary to obtain detailed information about pigment mixtures, additives, and paint stratigraphy. The presence of nearly identical pigment mixtures and fillers in both paintings strongly supports the hypothesis, based on stylistic qualities, that Picasso painted both pictures. The absence of a varnish or dirt layer between the two compositions similarly supports the suggestion that Picasso painted The Blue Room within only a few months of the portrait. Picasso's practice of reusing canvases is discussed by Hoenigswald [10] and McCully [16], and an increasing number of works from this transitional stage of Picasso's early career are known to be painted over another composition- some within only a short period of time. For example, Scène de la Rue (San Francisco Museum of Modern Art), dated 1900, is painted over a version of Le Moulin de la Galette [13]. The known work, in the collection of the Solomon R. Guggenheim Museum, is dated autumn 1900.

Microanalysis of paint samples also provided the first clues to Picasso's different approaches in painting the portrait and The Blue Room. Variegated color in the underlying paint layers suggested Picasso used a more direct approach in painting the portrait, applying relatively pure color and mixing paint wet-into-wet on the canvas. A very different approach is observed in The Blue Room. Here, while some direct wet-into-wet mixing of color is observed in the bouquet of flowers on the table, in general, uniformly blended surface paint layers imply Picasso deliberately mixed colors on the palette.
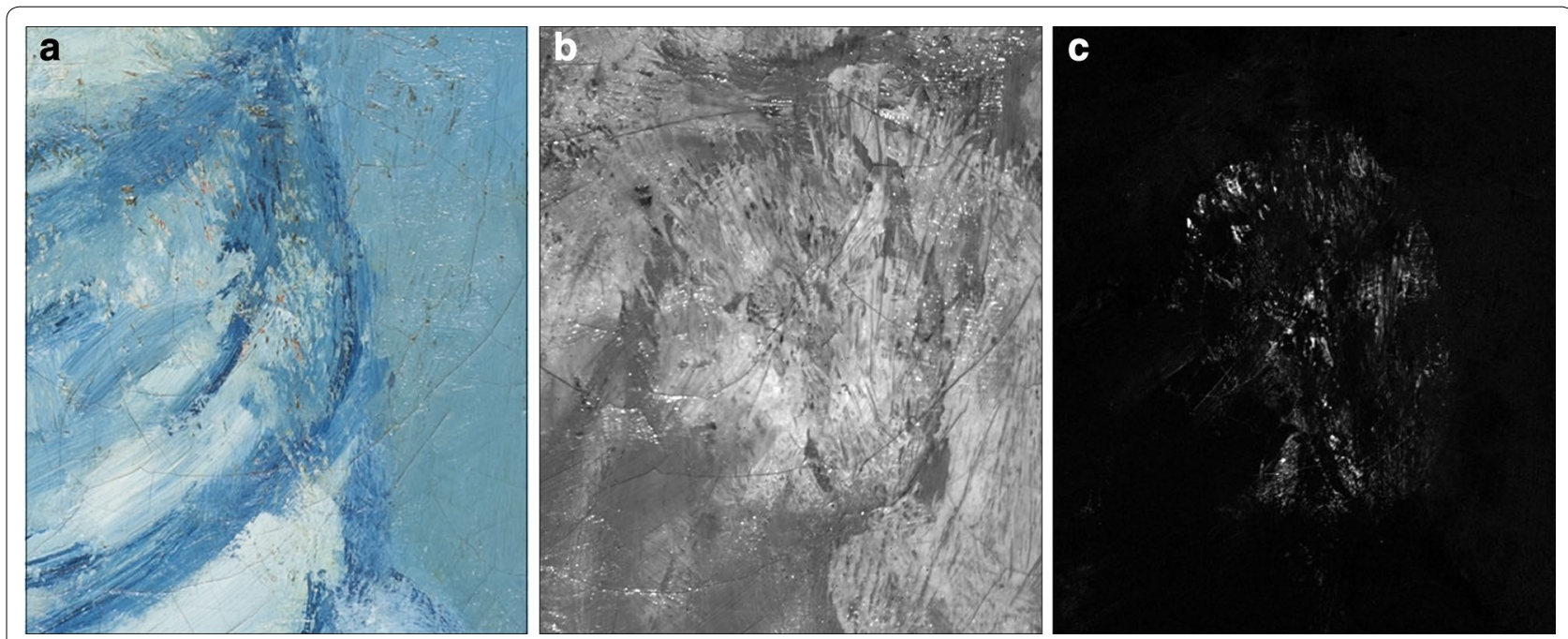

Fig. 15 Detail images of the same area in the center of The Blue Room (rotated $90^{\circ}$ clockwise) showing the oval object in the center of the man's shirt. a The area seen in visible light; $\mathbf{b}$ the IRR K-filter image (2100-2400 nm); and $\mathbf{c}$ the SR-XRF Hg map 


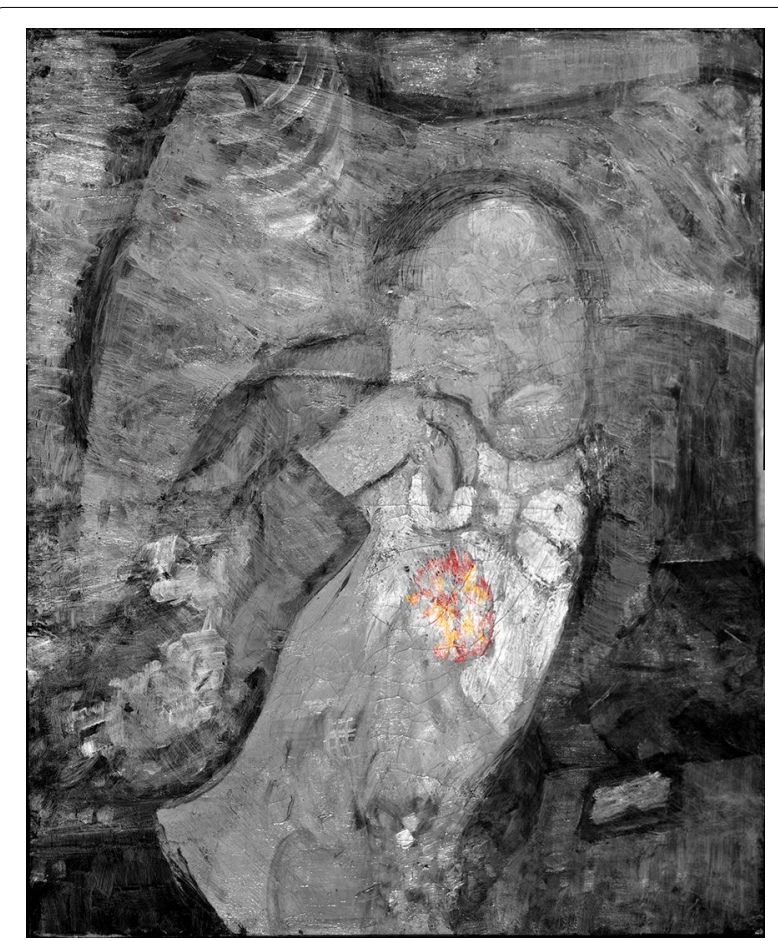

Fig. 16 IRR image (1500-700 nm) with estimated colorization in the region of interest. Using Photoshop CS5, areas of interest in the $\mathrm{Hg}$ and $\mathrm{Cr}$ SR-XRF maps were selected and converted to red and yellow, respectively. The registered colorized layers were superimposed on the IRR image to visualize color in the area of the flower

In particular, the use of zinc white throughout The Blue Room, whether on its own or mixed with other colors, with the consistent presence of barium sulfate filler, suggests Picasso mixed the various shades of blue, green, pink, and white himself. This is in agreement with Sabartes' description of Picasso's Blue period palette: "As a rule, the palette was on the floor. White, heaped in the center, constituted the basis of that type of mixture, which he prepared especially with blue. The other colors brightened the contours" [40].

The similarities in materials between The Blue Room and its underlying portrait presented a challenge for the non-invasive RIS and SR-XRF techniques. Both mapping techniques captured data from both paintings simultaneously, with differing transparencies and signal for each pigment in each technique. The absence of an intermediary ground layer, in part, complicated interpretation of the RIS results, while the amount and thickness of zinc white pigment throughout the surface layers was the biggest limitation for obtaining better SR-XRF results for the underlying painting.

However, the complementary nature of SR-XRF mapping and RIS techniques, which has been previously evaluated [41], proved beneficial to this study in the end. The combination of elemental mapping from SR-XRF and molecular mapping from RIS facilitated the identification of pigments and an understanding of Picasso's process in this complex work. For example, where the SR-XRF map for chromium indicates areas where chrome yellow, viridian, or chromium oxide green could be present individually or in combination, the RIS map for viridian specifically highlighted areas where the spectral endmembers for the pure, hydrated chromium oxide pigment were found. RIS was also able to identify pigments with only low-Z elements (e.g., ultramarine blue) that have weak signals in XRF techniques. Where RIS was limited in identifying mixtures, SRXRF mapping was able to differentiate between elemental components. For example, comparing the SR-XRF maps for iron, copper, and arsenic shows that all three elements are present in the background of the Toulouse-Lautrec poster, which suggests the artist used a mixture of Prussian blue and emerald green in these regions.

Results from both mapping techniques combined with targeted microanalysis led to a better understanding of Picasso's evolving use of color in the two paintings and added to the body of technical information about Picasso's early work. In addition, all methods of examination and analysis were necessary to the discovery a red flower on the front of the man's white shirt in the portrait, a significant compositional element that, with its odd placement (in the center of the shirt rather than on the lapel of the jacket), may aid researchers in eventually identifying the man in the portrait and possibly his significance, if any, in Picasso's early career.

\section{Additional files}

Additional file 1: Table S1. Summary of findings of cross-sectional analysis.

Additional file 2: Table S2. Summary of pXRF results.

Additional file 3: Table S3. $\mu$ Raman spectra, samples X6, X12, and X14 Colored peaks are as labeled. Numbered black peaks are unassigned.

Additional file 4: Table S4. $\mu$ FT-IR spectra, samples X1 (black) and X3 (yellow).

\section{Authors' contributions}

PF examined the painting, collected and processed InGaAs IRR, and documented painting history. JLM and AMH took paint samples and performed pXRF and microanalysis. JKD and KD collected and processed InSb IRR, $\mathrm{RIS}$, and infrared luminescence data. AW led SR-XRF data collection, which included JLM, AMH, AF, and PF. AF, AMH, and AW analyzed SR-XRF data. All authors were involved in drafting and revising the manuscript. All authors read and approved the final manuscript.

\section{Author details}

${ }^{1}$ The Phillips Collection, 1600 21st Street NW, Washington, DC 20009, USA.

${ }^{2}$ Conservation Department, Rijksmuseum Amsterdam, Postbus 74888, Amsterdam 1070 DN, The Netherlands. ${ }^{3}$ Scientific Research Department, National Gallery of Art, 4th and Constitution Ave NW, Washington, DC 20565 USA. ${ }^{4}$ Cornell High Energy Synchrotron Source, Rte. 366 \& Pine Tree Road, 
Ithaca 14853, NY, USA. ${ }^{5}$ Department of Chemistry, Duke University, Durham, NC 27708, USA. ${ }^{6}$ Scientific Analysis of Fine Art, LLC, Philadelphia, USA.

\section{Acknowledgements}

The authors wish to acknowledge Robin Kirkham, Gareth Moorhead, and Chris Ryan of CSIRO, Australia, and Anthony Kuczewski and Peter Siddons of Brookhaven National Laboratory for traveling to CHESS and providing access to and sharing their expertise with the Maia detector; Catherine Matsen and Gwénaëlle Kavich (Winterthur Museum) for assistance with microanalysis of paint samples; Damon Conover (George Washington University) for processing and registration of images; and Elizabeth Steele, Susan Behrends Frank, Eliza Rathbone, Dorothy Kosinski (The Phillips Collection), Ann Hoenigswald (National Gallery of Art), and Marilyn McCully (independent scholar) for consultation and continuing support of the project.

\section{Competing interests}

The authors declare that they have no competing interests.

\section{Funding}

JKD and KAD acknowledge support from the Andrew W. Mellon and Samuel H. Kress Foundations and the National Science Foundation (1041827). This work includes research conducted at the Cornell High Energy Synchrotron Source (CHESS) which is supported by the National Science Foundation and the National Institutes of Health/National Institute of General Medical Sciences under NSF award DMR-1332208.

\section{Received: 2 October 2016 Accepted: 6 March 2017}

Published online: 22 March 2017

\section{References}

1. Rubin W, Fluegel J. Pablo Picasso, a retrospective. New York: Museum of Modern Art; 1980. p. 26.

2. McCully M, editor. Picasso: The Early Years, 1892-1906. Washington: National Gallery of Art; 1997. cat. 71; p. 170.

3. Cowling E, Kendall R. Picasso looks at Degas. Williamstown, Mass: Sterling and Francine Clark Art Institute; 2010. Cat. 88; p.79.

4. McCully M, Picasso P, Bakker N, Cendoya I, Read P, Raeburn M. Picasso in Paris 1900-1907. New York: Vendome Press; 2011. pl. 56; p. 100.

5. Wright B, editor. Becoming Picasso: Paris 1901. 1st ed. London: The Courtauld Gallery in association with Paul Holberton Publishing; 2013.

6. Clark T. Picasso and truth, from cubism to guernica. Princeton: Princeton University Press; 2013.

7. Letter from Russell Quandt to Duncan Phillips, 1954. Object files, The Phillips Collection.

8. Nicolson B. X-Rays at agnews. Burlingt Mag. 1969;111(792):165-71.

9. Gedo M. A youthful genius confronts his destiny: Picasso's "Old Guitarist" in The Art Institute of Chicago. Art Inst Chic Mus Stud. 1986;12(2):153-65.

10. Hoenigswald A. Works in progress: Pablo Picasso's hidden images. In: McCully M, editor. Picasso: the early years, 1892-1906. Washington: National Gallery of Art; 1997. p. 299-309.

11. Beloli L. The evolution of Picasso's portrait of Gertrude Stein. Burlingt Mag. 1999;141(1150):12-8.

12. Belloli L. Lost paintings beneath Picasso's "La Coiffure". Metrop Mus J. 2005;40:151-8.

13. Hamlin J. It was the find of a lifetime-a Picasso buried under another Picasso. Now they're both on view at SFMOMA. San Francisco Chronicle [Internet]. 2007. http://www.sfchronicle.com/entertainment/article/ It-was-the-find-of-a-lifetime-a-Picasso-buried-2606969.php.Accessed 15 Sept 2016.

14. Belloli L, Digney_Peer S, Duvernois I, Mustalish R, Roth K. Technical Notes. In:Tinterow G, Stein SA, editors. Picasso in the metropolitan museum of art. 1st ed. New York: The Metropolitan Museum of Art; 2010. p. 16-258.

15. Vogel C. Under One Picasso, Another. The New York Times [Internet]. 2012. http://www.nytimes.com/2012/10/25/arts/design/under-a-picassopainting-another-picasso-painting.html?_r=0. Accessed 7 Sept 2016.

16. Picasso's McCully M, Practice Artistic. In: Wright B, editor. Becoming Picasso: Paris 1901. 1st ed. London: The Courtauld Gallery in association with Paul Holberton Publishing; 2013. p. 37-59.
17. Robinson CB. Picasso and the mysteries of life. La vie. London: D Giles Limited; 2013.

18. Gual M, Jiménez R, Robinson W. Journey through the blue: La Vie. BarceIona: Museu Picasso; 2013.

19. Bell I, Clark R, Gibbs P. Raman spectroscopic library of natural and synthetic pigments (pre- $\approx 1850$ AD). Spectrochim Acta Part A Mol Biomol Spectrosc. 1997;53(12):2159-79.

20. Price B, Pretzel B. Infrared and Raman Users Group Spectral Database. 1st ed. Philadelphia: IRUG; 2007; 2nd ed. Philadelphia: IRUG; 2009; Infrared and Raman Users Group Spectral Database. 2014. www.irug.org. Accessed 20 June 2014.

21. Craver C. The Coblentz Society desk book of infrared spectra. 1st ed. Kirkwood, MO (P.O. Box 9952, Kirkwood 63122): The Society; 1982 in Linstrom PMallard W. NIST chemistry webbook. 1st ed. [Washington, D.C.]: National Institute of Standards and Technology; 1997. Accessed online at Evaluated Infrared Spectra [Internet]. Webbook.nist.gov. 2017. http://webbook. nist.gov/chemistry/coblentz/. Accessed 6 Jan 2017.

22. Conover D, Delaney J, Loew M. Automatic registration and mosaicking of technical images of Old Master paintings. Appl Phys A. 2015;119(4):1567-75.

23. Thoury M, Delaney J, Rie E, Palmer M, Morales K, Krueger J. Near-infrared luminescence of cadmium pigments. in situ identification and mapping in paintings. Appl Spectrosc. 2011;65(8):939-51.

24. Kirkham R, Dunn P, Kuczewski A, Siddons D, Dodanwela R, Moorhead G, et al. The maia spectroscopy detector system: engineering for integrated pulse capture, low-latency scanning and real-time processing. In: AIP Conference Proceedings, 1234 (1). Melbourne, Australia: American Institute of Physics; 2010. p. 240-243.

25. Ryan C, Siddons D, Kirkham R, Li Z, de Jonge M, Paterson D, et al. Maia $X$-ray fluorescence imaging: capturing detail in complex natural samples. J Phys: Conf Ser. 2014;499:012002.

26. Howard D, de Jonge M, Lau D, Hay D, Varcoe-Cocks M, Ryan C, et al. High-definition X-ray Fluorescence elemental mapping of paintings. Anal Chem. 2012;84(7):3278-86.

27. Thurrowgood D, Paterson D, de Jonge M, Kirkham R, Thurrowgood S, Howard D. A hidden portrait by edgar degas. Sci Rep. 2016;6:29594.

28. Gervais C, Languille M, Reguer S, Gillet M, Vicenzi E, Chagnot S, et al. "Live" prussian blue fading by time-resolved $\mathrm{X}$-ray absorption spectroscopy. Appl Phys A. 2013;111(1):15-22.

29. Ryan C, Laird J, Fisher L, Kirkham R, Moorhead G. Improved Dynamic Analysis method for quantitative PIXE and SXRF element imaging of complex materials. Nucl Instrum Methods Phys Res, Sect B. 2015;363:42-7.

30. Delaney J, Walmsley E, Berrie B, Fletcher C. Multispectral imaging of paintings in the infrared to detect and map blue pigments scientific examination of art: modern techniques in conservation and analysis. Washington: The National Academies Press; 2005. p. 120-36.

31. Delaney J, Thoury M, Zeibel J, Ricciardi P, Morales K, Dooley K. Visible and infrared imaging spectroscopy of paintings and improved reflectography. Heritage Science. 2016;4(1):6.

32. Delaney J, Zeibel J, Thoury M, Littleton R, Palmer M, Morales K, et al. Visible and infrared imaging spectroscopy of Picasso's I Harlequin musician I: mapping and identification of artist materials I in situ I. Appl Spectrosc. 2010;64(6):584-94.

33. Howard D, de Jonge M, Lau D, Hay D, Varcoe-Cocks M, Ryan C, et al. High-definition X-ray fluorescence elemental mapping of paintings. Anal Chem. 2012;84(7):3278-86.

34. Dik J, Janssens K, Van Der Snickt G, van der Loeff L, Rickers K, Cotte M. Visualization of a lost painting by vincent van gogh using synchrotron radiation based $X$-ray fluorescence elemental mapping. Anal Chem. 2008;80(16):6436-42

35. Lowery G. N.C. Wyeth's coloring technique revealed by Cornell's synchrotron. Cornell Chronicle [Internet]. 2007; http://www.news.cornell. edu/stories/2007/07/nc-wyeths-coloring-technique-revealed-cornellssynchrotron. Accessed 15 Sep 2016.

36. Berrie B. Prussian Blue. In: Fitzhugh E, editor. Artists' pigments: a handbook of their history and characteristics, vol. 3. 1st ed. Washington: National Gallery of Art; 1997. p. 191-3.

37. Rosi F, Grazia C, Gabrieli F, Romani A, Paolantoni M, Vivani R, et al. UV-VisNIR and micro Raman spectroscopies for the non destructive identification of $\mathrm{Cd} 1-\mathrm{xZn \times S}$ solid solutions in cadmium yellow pigments. Microchem J. 2016;124:856-67. 
38. Monico L, Janssens K, Hendriks E, Brunetti B, Miliani C. Raman study of different crystalline forms of $\mathrm{PbCrO} 4$ and $\mathrm{PbCr} 1-\mathrm{xS} \times \mathrm{O} 4$ solid solutions for the noninvasive identification of chrome yellows in paintings: a focus on works by Vincent van Gogh. J Raman Spectrosc. 2014;45(11-12):1034-45.

39. Monico L, Janssens K, Miliani C, Brunetti B, Vagnini M, Vanmeert F, et al. Degradation process of lead chromate in paintings by vincent van gogh studied by means of spectromicroscopic methods. 3. synthesis, characterization, and detection of different crystal forms of the chrome yellow pigment. Anal Chem. 2013;85(2):851-9.

40. Sabartés J, Flores A. Picasso, an intimate portrait. New York: Prentice-Hall; 1948. p. 78.

41. Dooley K, Conover D, Glinsman L, Delaney J. Complementary standoff chemical imaging to map and identify artist materials in an early italian renaissance panel painting. Angew Chem. 2014;126(50):13995-9.

\section{Submit your manuscript to a SpringerOpen ${ }^{\circ}$ journal and benefit from:}

- Convenient online submission

\section{- Rigorous peer review}

- Immediate publication on acceptance

- Open access: articles freely available online

- High visibility within the field

- Retaining the copyright to your article 